University of Rhode Island

DigitalCommons@URI

Open Access Master's Theses

1977

\title{
A Flapping Wing Model for Avian Formation Flight
}

John D. Haffner

University of Rhode Island

Follow this and additional works at: https://digitalcommons.uri.edu/theses

\section{Recommended Citation}

Haffner, John D., "A Flapping Wing Model for Avian Formation Flight" (1977). Open Access Master's

Theses. Paper 738.

https://digitalcommons.uri.edu/theses/738

This Thesis is brought to you for free and open access by DigitalCommons@URI. It has been accepted for inclusion in Open Access Master's Theses by an authorized administrator of DigitalCommons@URI. For more information, please contact digitalcommons-group@uri.edu. 
A FLAPPING WING MODEL FOR

AVIAN FORMATION FLIGHT

BY

JOHN D. HAFFNER

A THESIS SUBMITTED IN PARTIAL FULFILLMENT OF THE REQUIREMENTS FOR THE DEGREE OF

MASTER OF SCIENCE

IN

ZOOLOGY

UNIVERSITY OF RHODE ISLAND

1977 


\section{MASTER OF SCIENCE THESIS}

OF

JOHN D. HAFFNER

Approved:

Thesis Committee

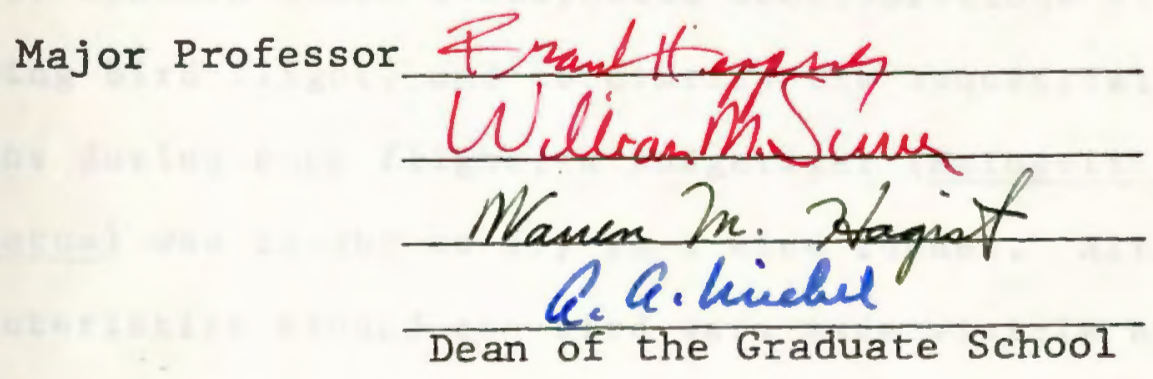

UNIVERSITY OF RHODE ISLAND 


\section{ABSTRACT}

There has been much speculation about the significance of avian formation flight, yet it's purpose is still unknown. To explain the phenomenon, two hypotheses have been proposed. The first describes linear formations, such as vee formations, as a function of the visual, social and spacial needs of the particular bird. The second hypothesis proposes that formation flight exists to conserve flight energy for the formation as a whole. The proposed conservation of flight energy is achleved by an overall reduction of in-flight drag, or by taking advantage of lift components of the vortex wake produced by the preceeding bird in the formation.

To confirm basic aerodynamic considerations of flapping bird flight, and to clarify the sequential wing actions during such flight, a Budgerigar (Melopsittacus undulatus) was taught to fly in a wind tunnel. Alrflow characteristics around the bird were made visible by directing a stream of chemical smoke into the tunnel. The bird was photographed during flight.

The photographic flight data were used in conjunction with data on formation flight geometry to construct a hypothetical model of a five bird vee formation. The model 
was subjected to analysis using standard aerodynamic principles to determine the extent of drag savings available to the birds in the formation.

The reduction in aerodynamic drag was much less than previously hypothesized, and the use of a fixed wing analogy for flapping flight was determined as an oversimplication. Previous aerodynamic studies of formation flight are discussed and compared to the results of this study, and investigation methods are proposed for further work which may provide answers to the question of a possible aerodynamic advantage to formation flight. 


\section{TABLE OF CONTENTS}

Page

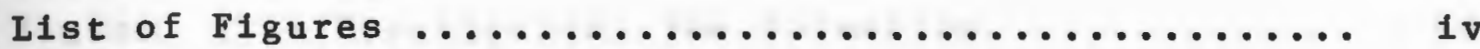

List of Tables ........................... vi

List of Photographs ....................... vil

List of symbols .......................... vili

Acknowledgements $\ldots \ldots \ldots \ldots \ldots \ldots \ldots \ldots \ldots \ldots \ldots \ldots \ldots \ldots \ldots$

Introduction $\ldots \ldots \ldots \ldots \ldots \ldots \ldots \ldots \ldots \ldots \ldots \ldots \ldots \ldots \ldots \ldots \ldots$

Literature Review .........................

Methods and Materials ....................... 22

Wind Tunnel Experimentation ................ 22

Review of Applicable Aerodynamic Principles ........ 29

Circulation and Lift .................... 29

Wing Vortex systems ..................... 32

Wing Forces and Trailing Vortex Drag ......... 36

Induced $\operatorname{Drag} \ldots \ldots \ldots \ldots \ldots \ldots \ldots \ldots \ldots \ldots \ldots \ldots \ldots \ldots$

Flapping Wing Aerodynamics ................ 47

Flapping Wing Vortices ................... 48

Blot-Sevart Law ....................... 52

Mode1 Parameters ........................... 55

Model Analysis ............................ 60

Results ................................ 68

Discussion and Conclusions .................. 78

Literature cited ......................... 92

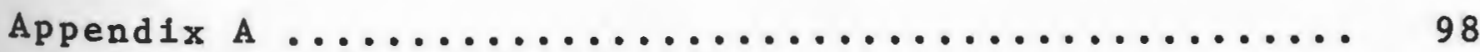




\section{LIST OF FIGURES}

Page

Figure 1 - Hypothet1cal Vee formation ........... 13

Figure 2 - Optimum formation configuration ....... 16

Figure 3 - Plexiglas flight cage............... 24

Figure 4 - Experimental wind tunnel ........... 27

Figure 5 - Airfoil cross section with stream

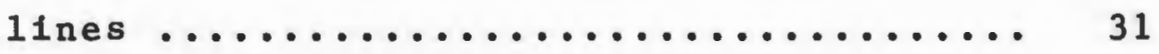

Figure 6a - Airfoll top view of horseshoe vortex ... 34

Figure $6 \mathrm{~b}-$ Single vortex segment .............. 38

Figure 7a - Alrfoll cross section showing down-

wash velocities ................. 40

Figure $7 b$ - Airfoil cross section with up and

downstream vertical air velocities ..... 42

Figure 7c - Trailing edge view of wing with wing

tip vertical air velocities ........... 44

Figure 8 - Flow conditions around a wing

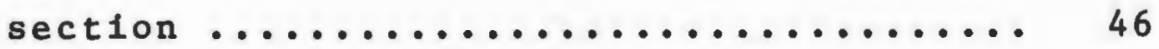

Figure 9 - Three-dimensional representation of

a complete vortex segment ........... 51

Figure 10 - Biot-Sevart equation ............... 54

Figure 11 - Action of hypothetical wing ......... 59

Figure 12 - Calculation of transverse vortex

Influence on adjacent birds ........... 65 
Figure 13 - Calculation of influence due to

trailing vortices $\ldots \ldots \ldots \ldots \ldots \ldots \ldots \ldots \ldots$

Figure 14 - Wing sections illustrating the thrust

and drag relationships during active

power and recovery strokes ............ 90 


\section{LIST OF TABLES}

\section{Page}

Table 1 - List of assumptions for the hypothetical formation flight model $\ldots \ldots \ldots \ldots \ldots \ldots \ldots \ldots \ldots \ldots \ldots \ldots \ldots \ldots \ldots \ldots \ldots \ldots$

Table 2 - Results of vortex Influence calculations $\ldots \ldots \ldots \ldots \ldots \ldots \ldots \ldots \ldots \ldots \ldots$ 


\section{LIST OF PHOTOGRAPHS}

Page

Photograph 1 - End of Power stroke.............. 71

Photograph 2 - Manus Al1gnment ............... 72

Photograph 3 - Maximum Aerodynamic Loading ......... 73

Photograph 4 - Downwash Behind BIrd ............. 74

Photograph 5 - Feathering Transition ............ 75

Photograph 6 - Unloaded Recovery .............. 76 


\section{LIST OF SYMBOLS}

$$
\begin{aligned}
& \Gamma \text { - Circulation Valve in } \mathrm{m}^{2} / \mathrm{sec} \\
& V \text { - Aerodynamic Velocity in } \mathrm{m} / \mathrm{sec} \\
& \omega \text { - Down Wash Velocity in } \mathrm{m} / \mathrm{sec} \\
& \epsilon \text { - Down Wash Angle in Degrees } \\
& \propto \text { - Angle of Attack in Degrees } \\
& \text { L - Lift in kg. } \\
& \text { Di - Induced Drag in kg. } \\
& \text { b - Wing Semi Span in Meters }
\end{aligned}
$$




\section{ACKNOWLEDGEMENTS}

I would like to express my appreciation to the following people for their assistance in the preparation of this thesis: Dr. Richard Lessmann helped me sort out the mysteries of aeronautics, Harold Pomeroy unselfishly gave me his time and assistance, Drs. Robert Shoop and Warren Hagist for reading this thesis and Dr. Frank Heppner for his encouragement and advice as my major professor and committee chairman. I also owe a special thanks to Dr. Clarence D. Cone, Jr. for his elegant work on flapping avian wing aerodynamics upon which my research was based. 


\section{INTRODUCTION}

This study was inftiated to investigate the hypothesis that flapping avian wing aerodynamics as described by Cone (1968) would establish a more accurate basis from which to construct a vee formation flight model, than the fixed wing analogies presented by authors of previous studies. Speculation about the significance of vee formation flight centers around two hypotheses. The first deals with purely social, physiological or behavioral reasons for the existence of vee formations. Forbush (1912) and Bent (1925) stated that vee flight formations allowed each bird room to work its wings and yet allow a clear view ahead. A variant of this view notes that the eyes of birds are fairly immobile and that the flight formations are necessary to keep the neighboring birds in view (Poncy, 1941; Van Wormer, 1968; Heppner, 1974).

The second hypothesis suggests that avian vee formation flight is a behavorial adaptation which allows the flock as a whole to conserve energy through the reduction of aerodynamic drag.

Lissaman and Shollenberger (1970) and Hummel (1973), among others, have proposed that an overall reduction in flight energy could be achleved by birds flying in a vee 
formation. Each succeeding bird in the formation would be in the rising component of the vortex wake of the bird or birds ahead. The theoretical models proposed by Lissaman and Shollenberger and by Hummel were not based upon aerodynamic data obtained from the study of flapping flight, but relied upon fixed wing analogies.

This study presents a theoretical model of a vee formation flight of Canada Geese which refines Lissaman and Shollenberger (1970) and Hummel (1973) models. This model assumes that the vortex wake of each bird within the formation adheres to the principles of flapping wing aerodynamics as described by Cone (1968). 


\section{LITERATURE REVIEW}

The Canada Goose was chosen to provide the basis for the vee formation flight model presented in this study. Th1s bird is most typically associated with the formation flight phenomina, and adequate data are avallable on the geometry of Its flight formations.

The Canada Goose (Branta canadens1s) is one of North America's largest waterfowl with an average wingspan of 1.52 meters and a body welght of 3.74 kllograms (Ruthven and Zimmerman, 1965). Geese are strong, graceful flyers and can maintain a cruising speed of 56.3 to $85.3 \mathrm{k110-}$ meters per hour (Preston, 1892; Tucker and Schmidt-Koenig, 1971) and can fly at top speeds of 96.5 kilometers per hour (Van Wormer, 1968).

Canada Geese live In close knit family groups. The young are kept with the parents until the beginning of the new breeding season, and the parents mate for life (Delacour and Mayr, 1945; Elder and Elder, 1949; Beer, $1958)$.

The Atlantic Canada Goose migrates in the fall from Its breeding grounds in southern Labrador, down the east coast of North America, to its wintering habitat in southeastern United States and northeastern Mexico (Hanson, 1965). 
Canada Geese migrate in large âgular formations belleved to be made up of numbers of families (Phillips, 1910; Elder and Elder, 1949; Beer, 1958). Darling (1952) suggested that the soclal behavior of flocklng, by virtue of its existence must have some survival value, but at present none has been shown. The formation of the flocks for migration may be due to several causes. Werth (1958) proposed that flocklng was an Innate behavioral character1stic, while Lorenz (1937) stated that flocking is initiated by the white vee-shaped area on the rump of the goose, which acts as an automatic release. Emlen (1952) and Collias (1952) suggested that flocking is a result of the decline of gonadal hormone activity. Darling (1938) observed that as large flocks are forming before migration, frequent practice flights are undertaken which probably lead to a uniformity of mood and synchronization of flight patterns.

The migration flights may cover more than two thousand miles (Hanson, 1965), but are not made all at once. The flocks move at a moderate pace, stopplng at selected areas along the migration route to rest and feed. Non-stop flights may not last more than 8 to 10 hours. At 80 k11ometers per hour, a 10 hour flight would carry the flock 800 k1lometers. Pennyculck (1969) mentioned that It would be Interesting to Investigate how long geese and swans, having high wing loadings, could fly at a given "fuel" load. 
Flight energy expenditures for birds can be as much as elght times the resting metabolism (Raveling and La Febvre, 1967); however the actual energy requirements may vary greatly from one specles to another due to differences in size, welght, and flight speed (Pennyculck, 1969; Nisbet, 1967; Schaefer, 1968). Energy for f11ght is obtained through the metabolism of fats (Tucker, 1971). One way to prepare for long migratory flights would be to engage in hyperphagla. Nisbet (1963), King and Farner (1965), and George and Berger (1966) noted that migratory fat deposition was primarily restricted to small passerine birds that migrate at night or over large ecological barrlers such as seas or deserts. The larger migratory birds such as geese and swans have the same proportion of flight muscle to body welght as smaller birds (Greenewalt, 1962), yet have higher wing loadings. It would seem that this combination of factors, lncluding the higher flight speeds, would dramatically increase the flight energy consumption and severely limit the non-stop flight range (N1sbet, 1967; Pennyculck, 1969). In fact, the opposite may be true. Schaefer (1968), after an analysis of bird aerodynamics, found that the power to welght ratio decreased very slowly from the smallest to the largest species, implying that the energy needed to fly a given distance is approximately inverse to the filght speed of the bird. It will be shown later that this observation also agrees with conventional fixed wing aerodynamics. 
The flight mode a bird engages in may also serve to reduce the overall energy needs of migratory flight. BIrds such as hawks and vultures conserve energy during flight by soaring on rising currents of alr (Davis, 1896; Raspet, 1950; Parrott, 1970). Long distances can be covered by utilizing alternate flapping and soaring flight. Austin (1961) noted that cormorants utilize this method of f1ight. Geese, however, have not been observed using any method of flight other than continuous flapping. Pennyculck (1969) has suggested that flight energles might be reduced by flying in areas of rising alr currents on the lee side of hills and mountain ranges. Flight over areas with high thermal activity would also benefit energy consumption during migratory filghts.

Any object that moves through a medium is Impeded by drag. As a bird flies through the alr a significant amount of the energy expended is used to overcome aerodynamic drag (Cone, 1968). The drag on a bird in flight is made up of two components; parasite drag and induced drag. Parasite drag is created by the resistance of a body moving through a fluid medium and has two main components, form drag and viscous drag. Form drag is a function of the streamiining of the form moving through the alr. Viscous drag or skin friction varies with the viscosity of the fluid medium and the roughness of the surface of the moving body. The amount of parasite drag produced is directly proportional to the speed of flight, while the magnitude of induced drag 
1s inversely proportional to flight speed (Dwinnel1, 1949; Parkinson, 1944). Induced drag arises from the rearward Inclination of the resultant lift vector on a $11 \mathrm{ft}$ producing body, and is present even for what aerospace engineers term a perfect fluld in which there is no parasite drag (Dwinne11, 1949). The magnitude of Induced drag is dependent upon the wing shape, bird weight and the flight speed. A large induced drag would be experienced by a heavy, slow flying bird with short, wide wings.

Birds that are not required to make long migratory flights or fly at high speeds for any distance may not need low drag wing and body conflgurations. Pheasants and quall have short stubby wings with unstreamlined bodies. The survival value of a low drag body form is lnsignificant in the habitats occupied by birds of this type. Passerines have body forms intermediate between low and high drag types. Most passerines are migratory, yet their life style and habitat dictate that they have relatively short wings for more maneuverable flight. Birds such as hawks and vultures fly at relatively slow speeds so that parasite drag is minimized.

Soaring birds have characteristically efficient highlift wings. High aspect ratio wings like those of the dynamic soaring birds produce a high lift to drag ratio. Savile (1957) suggested that the broad slotted wings of terrestrial soaring birds serve a dual purpose. The shorter, broader wing allows a more powerful flapping 
stroke needed to maneuver around obstacles, while maintaining the same wing area. The slotted wing tips compensate for the loss of lift to drag efficiency by smoothing the air flow over the wing tips. Cone (1968) concluded, after an extensive theoretical aerodynamic analysis of flapping flight, that the spreading and flexing of the primary feathers during soaring or flapping flight allowed a gradual reduction of pressure differences between the upper and lower wing surfaces thereby helping to reduce the magnitude of the wing tip vortex induced drag.

Birds that migrate over long distances at high speed have body forms that are adapted to creating the least amount of parasite and induced drag. Pennyculck (1969) pointed out that geese and swans have more streamlined bodies than most other birds, and their long, slender, pointed wings may be more efficient at minimizing induced drag at high speeds in flapping flight, than the square ended, slotted wings of static soaring birds.

In the above discussion on drag reduction, the principles cited are primarily associated with fixed wing systems. To accurately measure the total aerodynamic properties of bird flight, one must investigate the aerodynamics of the flapping wing system. The flapping wing can be considered as a mechanical oscilator being driven at various frequencles (Greenewalt, 1960). Tucker (1966) suggested that such a resonant system can attain a given amplitude of oscillation with a minimum of energy input and 
could be a device for conserving energy in flapping wing bird flight. Brown (1953) stated that the flexible structures of a bird's wing can have no flxed aerodynamic properties due to the constantly changing forces on the wing. A flapping-wing bird is a non-rigld flight system and the center of gravity is constantly changing with the distribution of the mass (Cone, 1968). The Induced drag created by the flapping wing and the associated vortex wake are the most complicated features of the aerodynamics of flapping flight. Both Cone (1968) and Raspet (1950) have stated that birds may even be able to gain energy from the vortex wake. Cone theorized that the vortex wake produced during certain elements of the flapping cycle would result In either no induced drag or even negative induced drag (thrust). Cone suggested that the largest portion of drag produced during flapping flight was 1nduced drag. Raspet (1960) proposed that further drag reduction could be achieved by the control of boundary layer vorticity using the selective porosity of bird feathers. Raspet noted that feathers were ten times more porous from top to bottom than In the other direction; this could minimize drag during the "recovery stroke" of the wing by reducing boundary layer turbulence.

Linear flight formations, as described by Heppner (1974), have been considered by many authors (Munk, 1933; Storer, 1948; Geyr von Schweppenburg, 1952; Sav1le, 1957 ; Terres, 1968; Nacht1ga11, 1970; LIssaman and Shollenberger, 
1970; Humme1, 1974) as a probable means of conserving flight energy by utilizing energy normally lost to the vortex wake. Forbush (1912), although 11ttle was known of aerodynamic principles at the time of writing, also foresaw some aerodynamic utility in formation flight though he described 1 t as breaking or smoothing of the air by the leading bird in the flock. Bent (1925) and Van Wormer (1968) also describe this as a possible function of 1inear formation flight.

Austin (1961) noted that vee or varlations of the vee formations are used generally by large heavy birds that have high wing loadings. Birds such as geese, swans, cormorants, pelicans, flamingos, storks, herons, and the larger ducks might have to expand proportionally larger amounts of energy for migratory flights than smaller, 11ghter birds. For them, energy saved by formation flight, would be highly beneficial.

Typical of the vortex use theories is that of Lissaman and Shollenberger (1970). Their hypothesis is based upon the geometry of the flight formation and the production of wing tip vortex wakes. The arrangement of birds in vee formations where the angle between the apex and legs varies between $27^{\circ}$ and over $90^{\circ}$ (Gould, 1972) would allow each bird in the formation to fly within the upwash field created by the wing tip vortex of the bird ahead (see Figure 1). This would enable a flock of birds to fly a given distance with less power needed to generate the 
lifting momentum than a bird flylng the same distance alone (Lissaman and Shollenberger, 1970). Lissaman and

Shollenberger have calculated that for an elliptically loaded wing (le. equal downwash behind the wing throughout the span) the optimum vee formation would have a vee angle of greater than $90^{\circ}$, becoming more swept at the end with a wing tip to wing tip spacing of less than one-tenth of the span.

Using a method of radar tracking, Williams and Klonowski (1976) found a greater variation in vee angles between separate formations. The measured vee angles varied between $38^{\circ}$ and $124^{\circ}$. The differences in measured and calculated vee angles as described by Gould and Heppner (1974) and those of Williams and Klonowski (1976) may be due to inherent differences in the data gathering techniques used by the authors. Gould and Heppner's optical technique enabled them to measure relatively small formations while Williams' radar technique could only resolve larger formations that may be too poorly organized at the apex to be measured by Gould and Heppner's optical method (Williams and Klonowski, 1976).

Lissaman and Shollenberger (1970) polnted out that even the bird at the apex of the formation would recelve a drag savings due to the upwash created by the birds behind, as described In Munk's (1933) stagger theorum. Hummel (1973) suggested that the geometry of the formations is most important. He stated that the individual at the apex 
Figure 1. A hypothetical vee formation of five birds showing the average vee angle and distance between birds along the arms of the formation, as described by Gould (1972). Distance $X$ is determined by the flight speed and power stroke duration. Distance $Y$ between vortex segments is determined by the flight speed and the time needed to complete the feathering, recovery and manus alignment phases of the flapping cycle. The dashed rectangles represent two complete vortex units created by bird b. during two flapping cycles. 
13

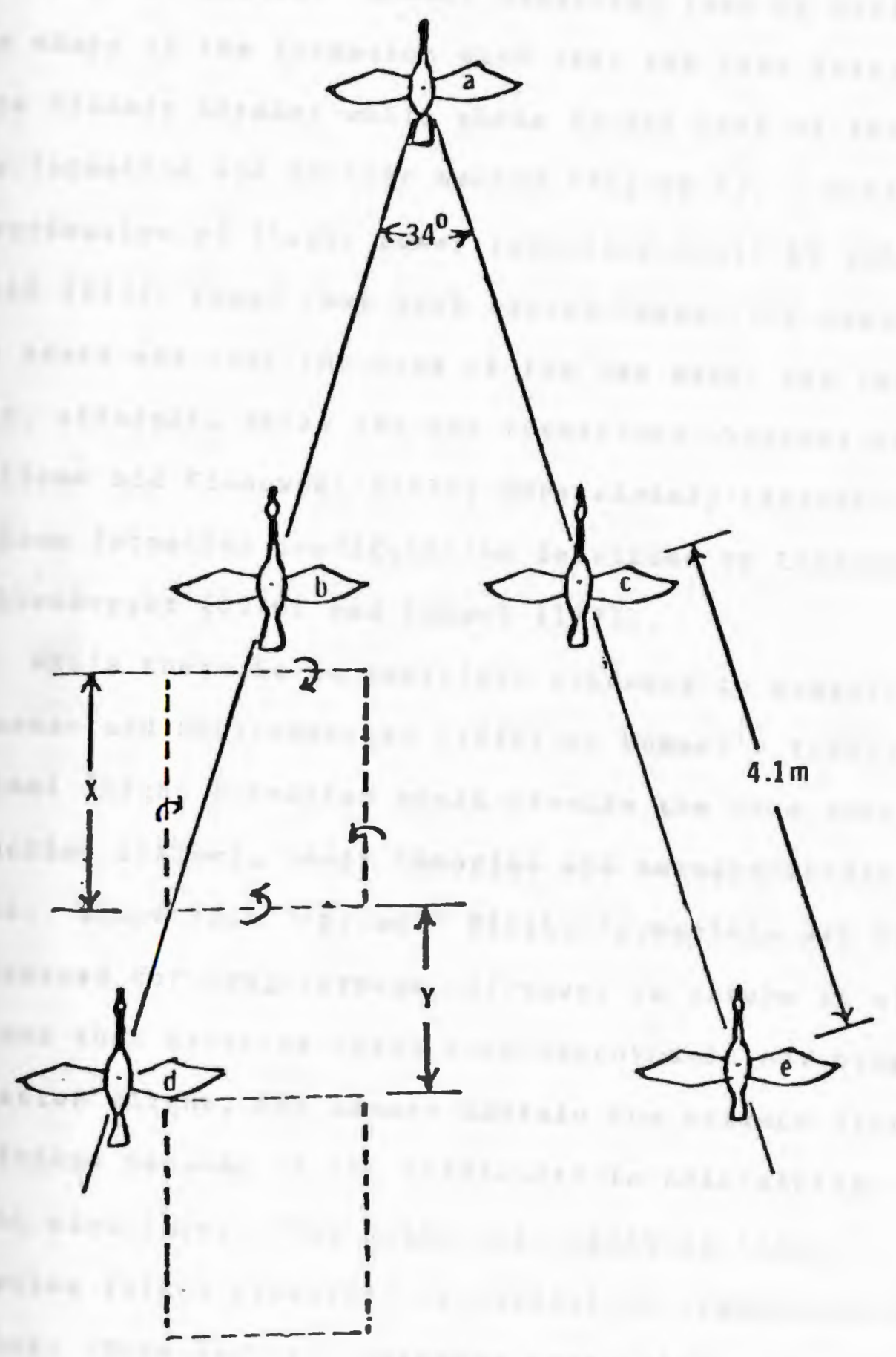


of a straight-sided formation has the smallest reduction in flight power demand. Hummel suggested that by modifying the shape of the formation such that the lead birds are more closely abreast while those at the ends of the arms of the formation are further behind (Figure 2), a uniform distribution of flight power reduction would be achleved. Gould (1972) found that with Canada Geese, the apex angle was acute and that the arms of the vee were, for the most part, straight, while the vee formations observed by W1111ams and Klonowsk1 (1976) more closely resemble the optimum formation configuration described by Lissaman and Shollenberger (1970) and Hummel (1973).

While there is no empirical evidence to suggest that Lissaman and Shollenberger (1970) or Hummel's (1973) optimal flight formation would provide the even power reduction claimed, their theories are aerodynamically sound. Since such "optimal" flight formations are rarely maintalned for long periods, if ever, in nature it might be assumed that geese may gain some aerodynamic advantage from formation filght, but cannot sustain the optimum filght conditions because of the difficulty in maintaining a rigid flight structure. They might also maintain linear formation flight primarily for social or communicative reasons. Some authors contended that flight formations serve purposes other than aerodynamic ones (Queeney, 1947; Franzisket, 1951; Ham11ton, 1967), and offered the explanation that linear formation flight provided an area of 
Figure 2. Optimum formation configuration for equal distribution of drag reduction $x_{1}$ and $x_{2}$ are average distances between bird wing tips (Hummel, 1973).

$$
x_{1}=x_{2}
$$


turbulence-free alr to fly In, and yet maintained a high degree of visual contact with the rest of the flock and a clear view ahead. Franzisket (1951) argued that wing tip vortex energy was Insignificant in its benefit to the flock. Hamilton (1967) further proposed that the flight of large numbers of birds in one group enhanced the accuracy of navigation. A flock would take the direction preferred by the majority of the members. Keeton (1971) showed that single pigeons navigated as well as large groups flylng together. However, it may be that the quality of the navigational abilities of pigeons in general are far superior to those of other birds. Heppner (1974) suggested that vee or echelon formations could be a method by which each bird in the formation could keep the image of neighboring birds in maximum resolution on the fovea. Heppner pointed out that the eyes of birds which are generally assoclated with linear formations are relatively 1mmobile. A bird with its head pointed in the direction of flight, sees areas of clearest vision ahead and to either side. Hanson (1965) reported that vocalization during flight may serve to maintain contact and keep the flock together. His hypothesis suggests that visual communication may not play as important a role In formation flight as previousiy thought.

Another condition often imposed on the wing tip energy theory of linear formation flight is that some sort of wing beat phase relationship must be demonstrated by successive 
birds in formation. Geyr von Schweppenburg (1952) stated that a wing beat phase relationship was necessary for the formation to achleve any aerodynamic advantage from linear formation flight. Geyr von Schweppenburg suggested that if the wing tip vortex were to be used to minimize induced drag, the vortex must be encountered by the wing of the following bird during a power stroke. If the vortex is encountered during the recovery stroke the advantage is wasted because no induced drag is generated by the aerodynamically unloaded outer section of the wing. Nachtigall (1970) demonstrated a precise phase relationship in the wing beats of geese flying in vee formations using film analysis techniques. Nachtigall found that the farther out along the arms of the vee formation the geese are located, the later thelr wings achleve a given stroke position. The difference in stroke between immediate neighbors remained more or less constant. The bird at the apex generally established the wing beat rhythm for the formation, however, Nachtigall (1970) observed as many as five separate phase relationships within a single large vee formation, each operating in a separate section of the formation. Gould (1972) and Berger (1972), using cline film analysis, were not able to find a constant wing beat phase relationship in Canada Geese and therefore concluded that any aerodynamic facilitation from linear formation flight was unlikely. The question of wing beat phase relationships is still unresolved; the conflicting evidence 
may be due to inadequate analysis techniques. The use of modern computer analysis in confunction with oscillation theory and improved data acquisition techniques may be the best way to resolve the question. A phase relationship may not be necessary for the utilization of wing tip vortex energy.

Poncy (1941) based his hypothesis concerning vee formation angles on the anatomical form of the birds. Poncy stated that after many years of observation the vee angles observed were due to the ability of the bird to see past its wing tips to remain in contact with the other birds in the formation. He 11lustrated this with drawings of three different formations. The neck length to wing spread ratio for Avocet (Recurvirostra avocetta) results in an obtuse vee angle due to the short necks of these birds. Great Cormorants (Phalacrocorax carbo) with necks longer than the Avocet, form vee formations with less obtuse angles. The Greater Flamingo (Phoenlcopterus ruber) with Its long neck forms a vee angle of almost $90^{\circ}$. All angles, Poncy stated, are directly influenced by the neck length and amount of room for wing flapping. It is not known how Poncy measured the angles of the formations he observed.

Gould (1972) and Heppner (1974) suggested that measurements of actual alr flow conditions around the wings of birds in flapping flight would be needed to determine if the wing tip vortex geometry and forces involved, were adequate to support the vortex energy capture theory of vee 
formation fllght. Heppner (1974) suggested Tucker's (1968) techniques of flying birds in wind tunnels might be adapted to this end. Brown (1952) used the wind tunnel to measure the lift produced by a portion of a bird's wing at different angles of attack. Brown's results showed that the bird's wing was highly resistant to stalling because the Individual feathers were allowed to maintain their angle of attack as the wing was rotated in the air stream. Ellassen (1963) showed the Importance of the ventral wing surface as a metabolic heat radiator by training a bird to glide In a wind tunnel. A walking or running mamal expends 10 to 15 times more energy to cover a given distance than a bird of the same slze does (Tucker, 1971). Some birds may be even more efficient than machines; the Canada Goose may be able to fly on less energy pound for pound than a jet transport. Le Page (1923) investigated the aerodynamics of a stuffed Pariah Kite in a wind tunnel; and Feldmann (1944) used a plaster model of a gull to Investigate the $11 f$ to drag ratios of birds. Parrot (1970) Investigated the aerodynamics of a living Black Vulture tralned to fly in a wind tunnel as did Tucker and Parrot (1970) with the Lagger Falcon. Schnitzler (1972) used the wind tunnel to Investigate the flight speeds of the Wh1te-crowned Sparrow.

The aerodynamics of flapping bird flight can be explained In terms used for modern fixed wing aerodynamics (Cone, 1968). However, this method is accurate only for 
the most general of calculations of aerodynamic parameters. A true mathematical picture would involve an exceedingly complex analysis and integration of all the physical and aerodynamic characteristics of the bird as a whole during flappling flight. The many questions that are associated. with the formation flight of birds such as the Canada Goose, especially those concerning the use of vortex wake energy while in formation flight, can only be answered by a thorough analysis of flapping wing aerodynamics. Providing an accurate and detalled mathematical model for flapping flight may prove to be beyond present technology, however a representation of the air flow around and behind a flapping wing could be demonstrated by adapting F. N. M. Brown's (1952) method of flow visualization using smoke streams in a wind tunnel, with Tucker's (1966) wind tunnel techniques. 


\section{Methods and Materials}

\section{Wind Tunnel Experimentation}

Data Acquisition

Investigation of the hypothesis of energy conservation as a function of linear formation flight hinges upon two main areas of information: the aerodynamic character of the vortex wake of a flapping bird; and the geometry of the flight formation.

The essence of this investigation and the basis for all data analysis is the formulation of an accurate aerodynamic model of flapping flight. To confirm some of the aspects of the nature of a flapping wing system as described by Cone (1968), the flapping flight of a Budgerigar (Melopsittacus undulatus) was photographed while the bird flew in a wind tunnel.

The Budgerigar was trained to fly in a wind tunnel, by placing the bird in a $50 \times 76 \mathrm{~cm}$. Plexiglas flight chamber, the front, bottom and rear of which was screened in with parallel $1 \mathrm{~mm}$. copper wires (Figure 3 ). The wires were connected to a Sears electronic fence charger through a series of resistors to selectively lower the current.

The birds were initially trained to sit only on a perch offered through the bottom of the chamber. After 
Figure 3. Plexiglas flight cage showing how the electrified copper wires are inserted to cover the open cage ends and bottom.

A. Open ended Plexiglass box.

B. $1 \mathrm{~mm}$. copper wire electrified grid. Wires pass over open ends and along the bottom of the cage.

C. Wooden hold down legs. 


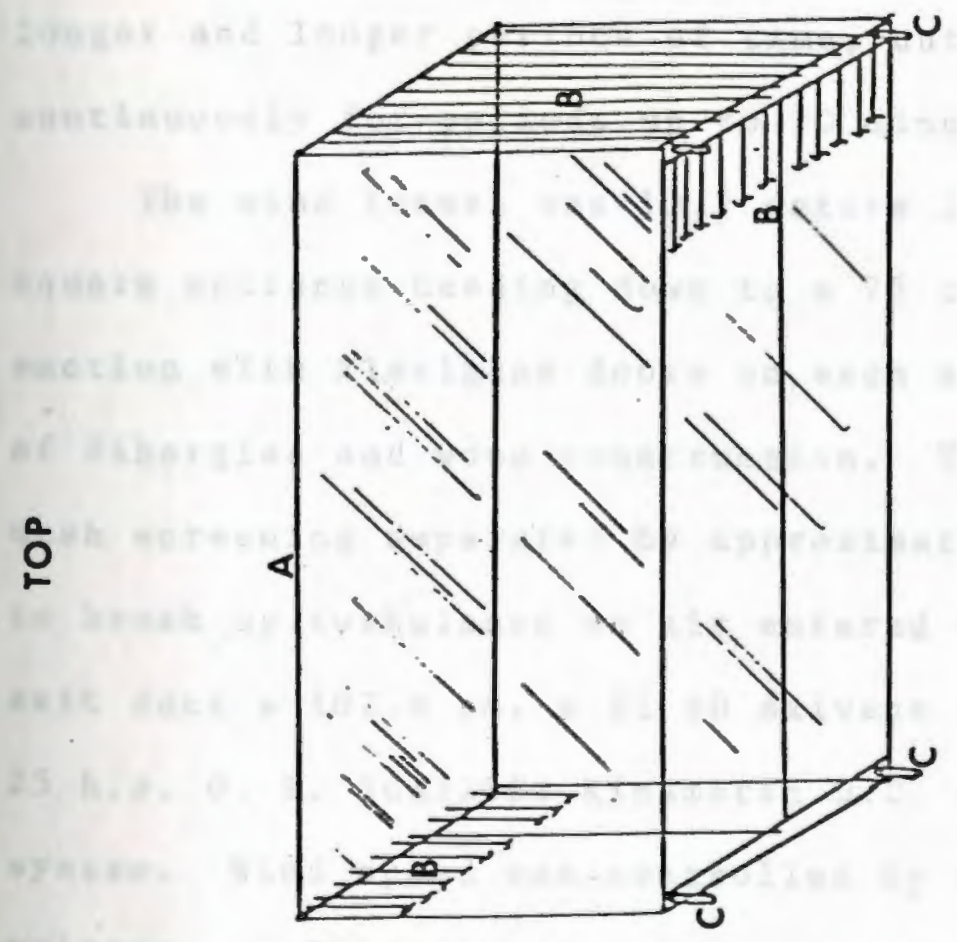


this was accomplished, the chamber was placed into the working section of the wind tunnel. The bird was allowed to remain on the perch while the tunnel was run up to a speed of approximately 9 meters per second. The perch was removed and the bird was not allowed to land in the chamber until the perch was returned. After about 2 to 3 hours of tralning spread out over several days the birds were well trained and flew whenever the perch was removed. After the inftial training the birds were exercised every day for longer and longer perlods of time, untll they could fly continuously for periods up to 20 minutes.

The wind tunnel was 13.7 meters long with a 3.6 meter square entrance heading down to a $75 \mathrm{~cm}$. $x 75 \mathrm{~cm}$. working section with Plexiglas doors on each side. The tunnel was of Fiberglas and wood construction. Three layers of $3 \mathrm{~mm}$. mesh screening separated by approximately $30 \mathrm{~cm}$. were used to break up turbulance as air entered the tunnel. In the exit duct a $107.9 \mathrm{~cm}$. $x 21$ BD Axivane fan was driven by a 25 h.P. G. E. 5CA326El Kinamatic D.C. motor through a belt system. Wind speed was controlled by varying the armature voltage. A Thermosystem, Inc., Model 4100 air flow meter was used to measure the flow velocity (Figure 4).

To visualize the alr flow around and behind the wing, a smoke stream was introduced through the tunnel entrance by placing a smoke distribution pipe immediately in front of the mesh screens. The smoke was produced by burning a 3 minute Safe Vue white smoke candle in a five gallon metal 
Figure 4. Side view of the experimental wind tunnel with: smoke generator and manifold A, mesh screening B, alrspeed detector C, flight cage with perch D, motor E, and fan F. 


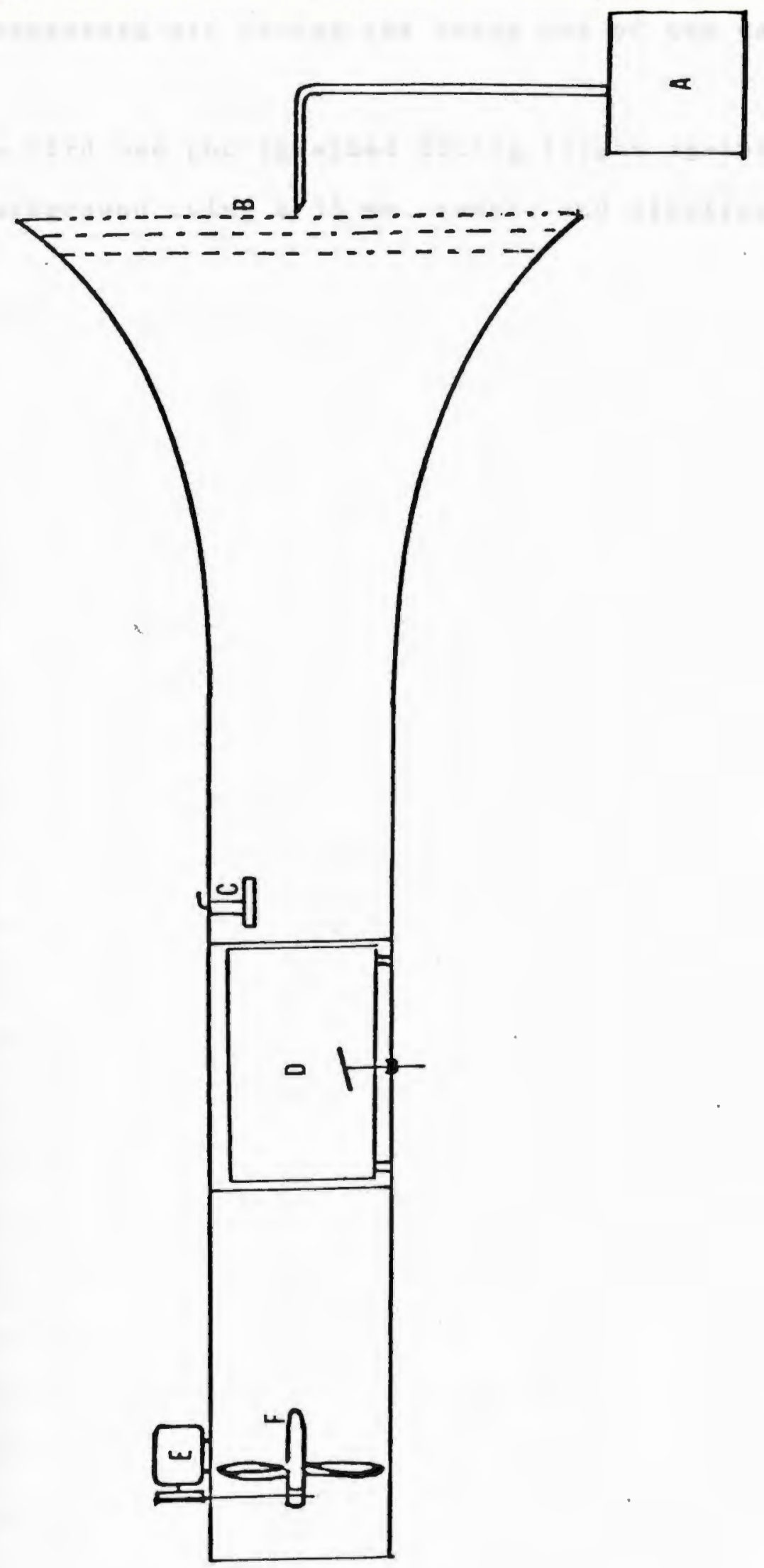


can. Compressed air forced the smoke out of the can to the pipe.

The bird was photographed during flight against a black background using a $35 \mathrm{~mm}$. camera and electronic flash system. 


\section{A Review of Applicable Aerodynamic Principles}

Circulation and Lift

Figure 5 represents the flow around a section profile of a wing of infinite length. The section is moving through the air at velocity $V$ and meeting the oncoming flow at an angle of attack $\alpha$. Due to the characteristics of the airfoll and the angle of attack, the pressure on the upper wing surface is less than that on the bottom surface. Bernoulli's equation for incompressible fluids demonstrates that the air flows faster in the low pressure area and slower in the high pressure area. The result is a velocity of $v_{u}$ on the upper surface and $v_{L}$ on the lower surface $\left(v_{L}<v<v_{u}\right)$. The resulting velocity difference can be thought of as the result of a vortex of strength originating within the center of the profile and running spanwise normal to the opposing air flow. A vortex is a core of alr or fluid rotating as though it were a solid; and around which air or fluid flows in concentric circles (Houghton and Brock, 1960). The Kutta-Joukowsky 1aw indicates that lift is proportional to the circulation where circulation is defined as "the line integral of the tangential velocity component round any closed circuit in the fluid" (Houghton and Brock, 1960). Increasing pressure 
Figure 5. A cross section of an alrfoll showing stream lines and relative afrflow velocities above and below the wing section which result from the Influence of the bound vortex with a circulation of $\Gamma$.

$v$ is the velocity of the undisturbed air.

$V_{u}$ is the velocity of the air flowing over the a $1 \mathrm{rfo11}$

$V_{L}$ is the velocity flowing under the airfoll. 
31

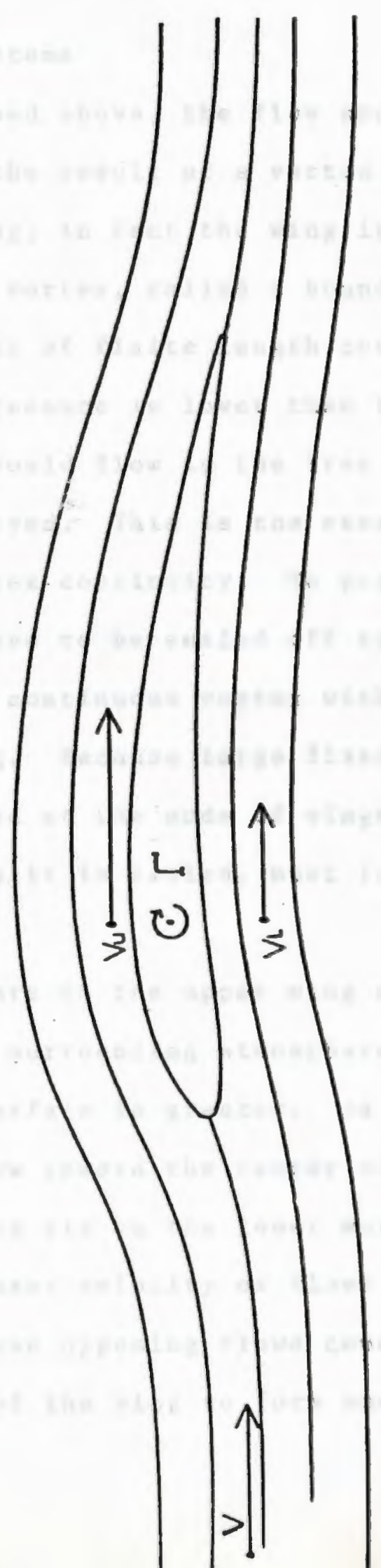


differences result in increasing the circulation and therefore the lift.

\section{Wing Vortex Systems}

As described above, the flow around a wing can be thought of as the result of a vortex running spanwise through the wing; in fact the wing itself could be thought of as a single vortex, called a bound vortex. In reality, a vortex segment of finite length could not exist. Since the interior pressure is lower than the surrounding pressure, air would flow in the free ends and the vortex would be destroyed. This is the essence of Helmholtz's theorem of vortex continulty. To persist, the vortex ends would either have to be sealed off by solid plates at the ends or form a continuous vortex with no free ends similar to a smoke ring. Because large fixed physical barriers cannot be placed at the ends of wings, the wing vortex or bound vortex as it is called, must form a continuous circuit.

The pressure on the upper wing surface in motion is lower than the surrounding atmosphere, while the pressure on the lower surface is greater. As a result air has a tendency to flow toward the center of the wing on the top surface, and the air on the lower surface either flows inward at a lesser velocity or flows outward toward the wing tips. These opposing flows come in contact at the tralling edge of the wing to form small longitudinal 
Figure 6. A top view of a wing with hypothetical spanwise bound and longltudinal trailing vortex filaments forming a horseshoe vortex pattern. (Adapted from Houghton and Brock, 1960) 


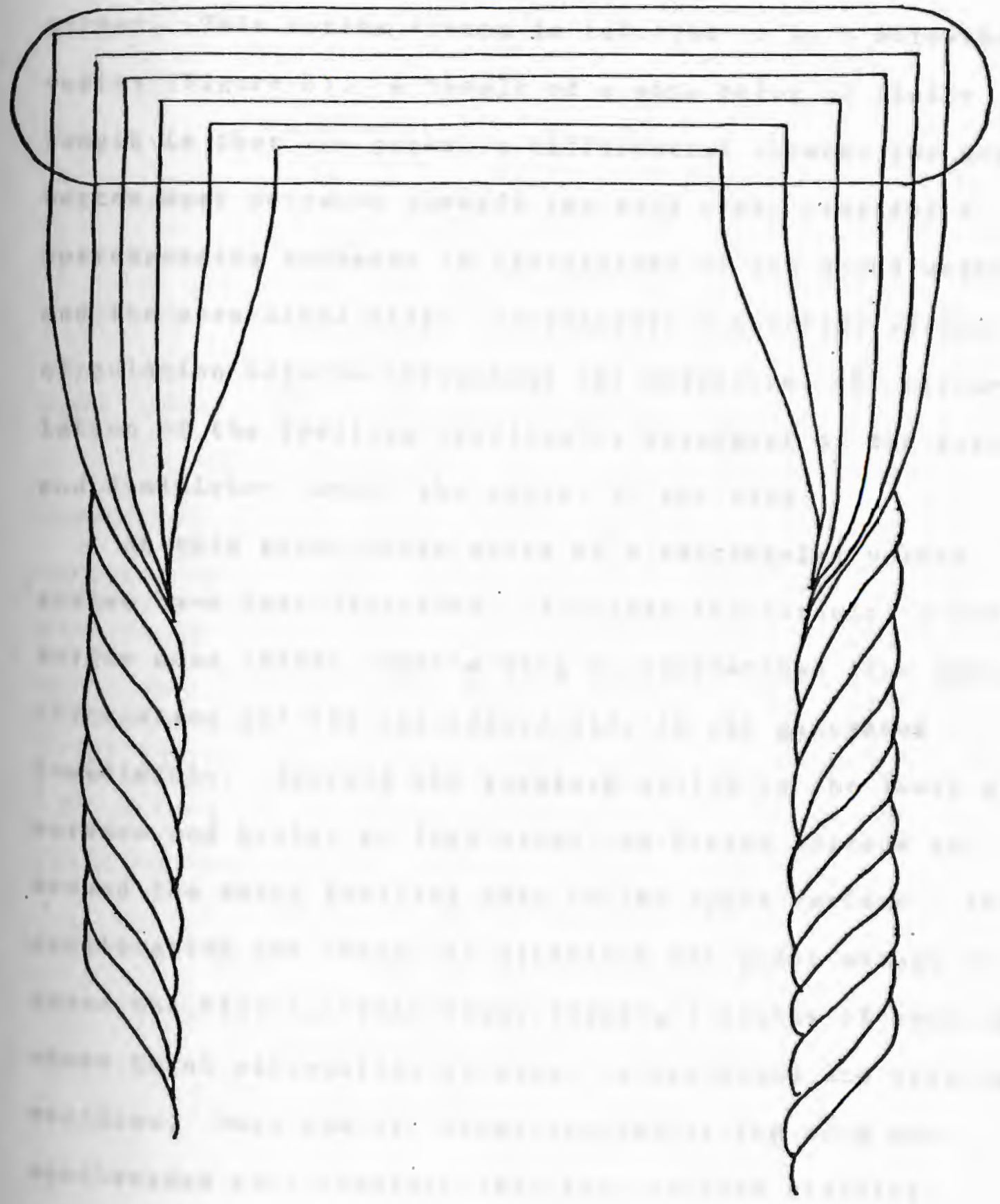


(streamwise) vortices distributed along the whole span. The small vortices coalesce into two large trailing vortices each with a total circulation equal to the bound vortex. This vortex system is referred to as a horseshoe vortex (Figure 6). A result of a wing being of finite length is that the pressure differential between top and bottom must decrease towards the wing tips, creating a corresponding decrease incirculation of the bound vortex and 1 ts associated $11 \mathrm{ft}$. To maintain a constant vortex circulation balance throughout the horseshoe, the circulation of the tralling vortices is strongest at the tips and diminishes toward the center of the wing.

At this point three sides of a rectangular vortex system have been described. To close the circult, a fourth vortex must exist. When a wing is accelerated from rest, circulation and its associated lift is not generated immediately. Instead alr pressure builds on the lower wing surface and begins to flow along the bottom surface and around the sharp trailing edge to the upper surface. The acceleration and change in direction are great enough to cause the flow to break free, forming a series of vortices whose total circulation is equal to the bound and trailing vortices. Once the alr along the top of the wing has accelerated to a constant velocity, no more starting vortices are shed from the wing. These inftial vortices may combine to form a single vortex with a rotation opposite that of the bound vortex and is called a 
"starting" vortex (see Figure 6-B). Similarly, when the wing is decelerated from a constant velocity to zero, the circulation of the bound vortex must decrease to zero. To accomplish this, component vortices making up the total bound vortex are shed from the wing at a rate that is proportional to the rate of deceleration. If the wing decelerates to zero at a high rate, the vortices shed will form a single stopping vortex equal in circulation and direction to the previously bound vortex.

Wing Forces and Trailing Vortex Drag

The influence on the flow of alr around the wing caused by the wing vortex system results in an overall downwash downstream of the wing. Figure 7 shows the downwash magnitude around the wing caused by the trailing vortices. Figure 7-B illustrates the combined effects of bound vortex and the trailing vortices and Figure 7-C shows the vertical velocities at the wing tips due to the trailing vortices.

Induced Drag

The consequences of downwash are twofold. First, as a result of Newton's third law of motion, lift is proportional to the amount of alr displaced downward. Secondly, the downwash creates an aerodynamic drag called induced drag. Figure 8 shows a typical wing section moving at velocity $V$ and angle of attack $\alpha$. As a result of the downwash velocity $W$ the alr flow passing the wing is 
Figure 6-B. Hypothetical single vortex segment shed from a flappling wing during a power stroke showing circulation directions:

a. Bound or stopping vortex.

b. and c. Wing tip trailing vortices.

d. Starting vortex.

e. Direction of flight. 
38

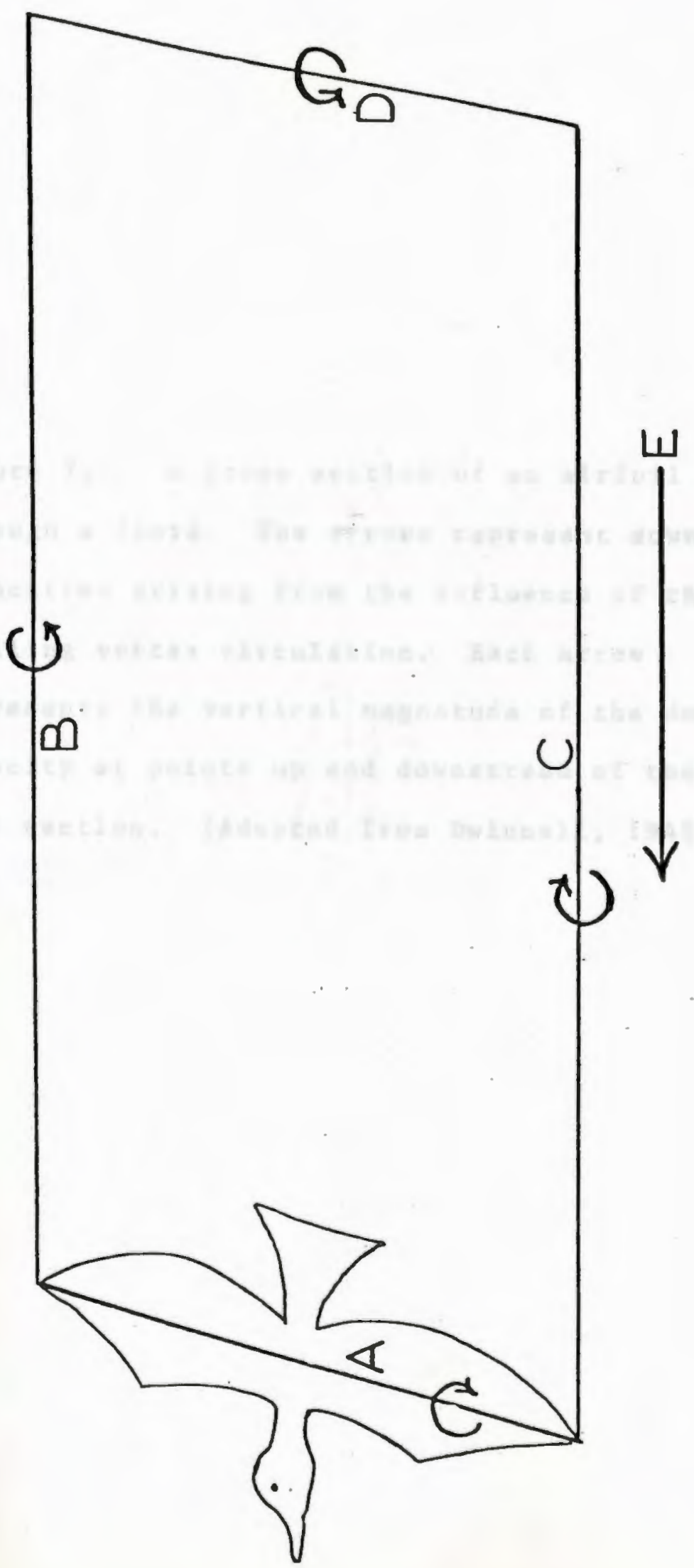


Figure 7. A cross section of an airfoil moving through a fluid. The arrows represent downwash velocities arising from the influence of the trailing vortex circulation. Each arrow represents the vertical magnatude of the downwash velocity at points up and downstream of the airfoll section. (Adapted from Dwinne11, 1949) 


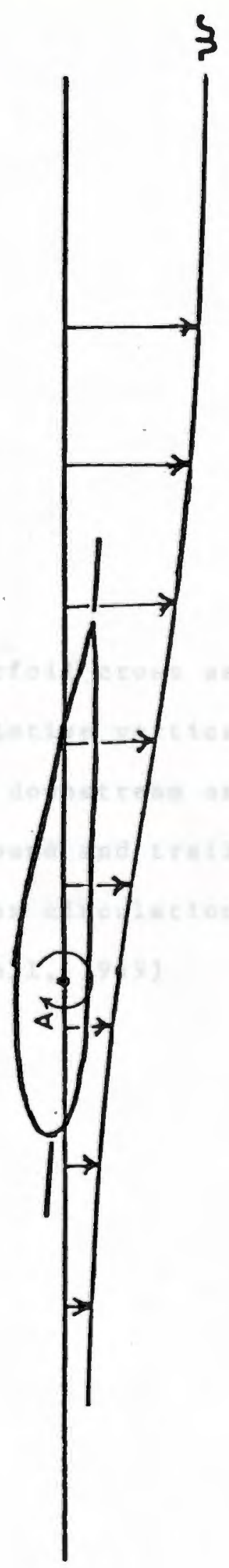


Figure 7-B. A alrfoll cross section with arrows 1llustrating the relative vertical alr velocities Induced both up and downstream as a result of the Influences of the bound and trailing vortices.

$$
a=\text { Bound vortex circulation. }
$$

(Adapted from Dwinnel1, 1949) 


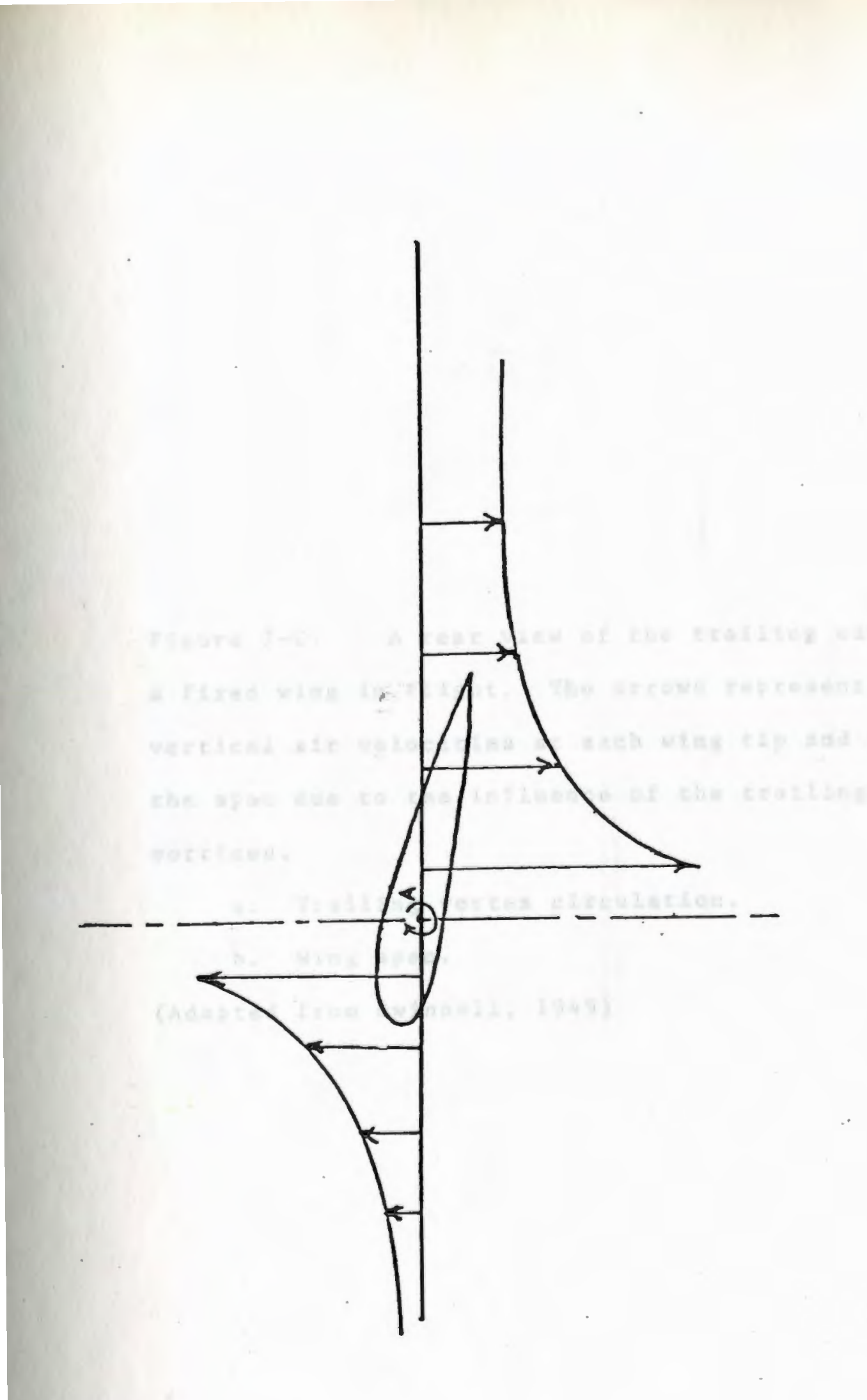


Figure 7-C. A rear view of the trailing edge of a fixed wing in flight. The arrows represent the vertical air velocities at each wing tip and along the span due to the influence of the trailing vortices.

a. Trailing vortex circulation.

b. Wing span.

(Adapted from Dwinne11, 1949) 


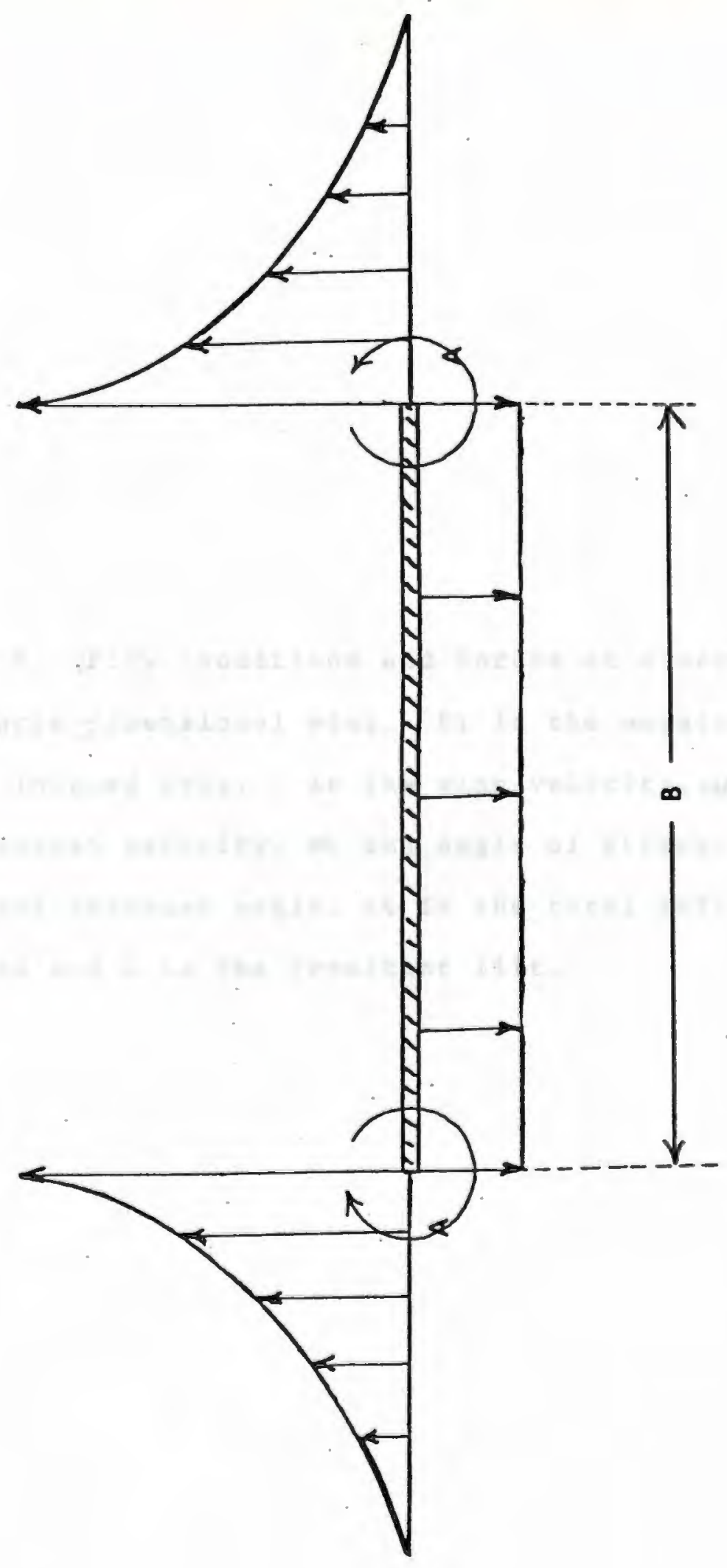


Figure 8. Flow conditions and forces at a section of a three-dimensional wing. Di is the magnitude of the induced drag, $V$ is the wing velocity, $w$ is the downwash velocity, $\alpha$ the angle of attack, 6 resultant downwash angle, Lt is the total $11 \mathrm{ft}$ produced and $L$ is the resultant lift. 


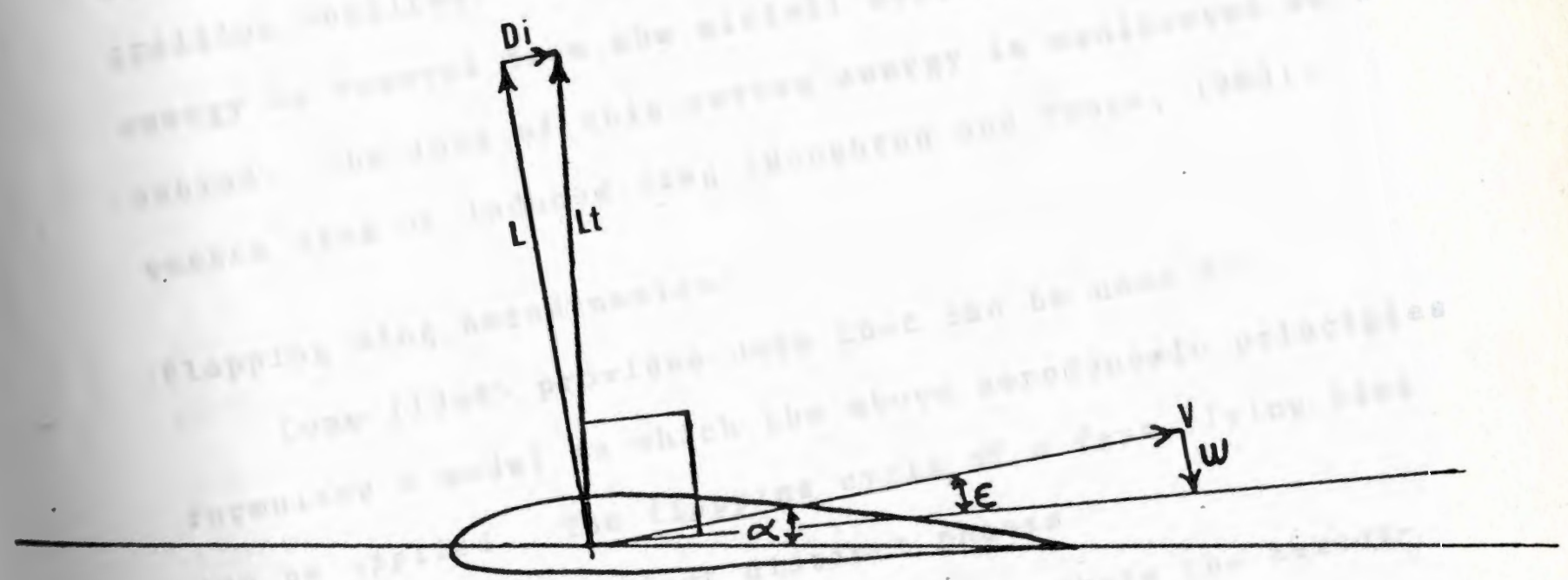


deflected downward at an angle $\boldsymbol{E}$, the downwash angle. The total lift vector $I_{t}$ can be resolved into the aerodynamic forces $L$ and $D_{1}$ respectively. $L$ is the vertical 11 ft and $D_{1}$ is induced drag force. A finite airfoll spins the afrflow near the wing tips into what eventually become the trailing vortices. To generate these vortices kinetic energy is removed from the airfoil system and is left behind. The loss of this vortex energy is manifested as a vortex drag or Induced drag (Houghton and Brock, 1960).

Flapping Wing Aerodynamics

Cone (1968) provides data that can be used to formulate a model to which the above aerodynamic principles can be applied. The flapping cycle of a fast flying bird can be described in four distinct phases.

1. The power stroke is the phase where the aerodynamic forces on the wing are producing both $11 \mathrm{ft}$ and thrust, and begins at the instant the wings become fully loaded aerodynamically and are being accelerated forward and downward relative to the body. The power stroke ends when the wing pinfons become aerodynamically unloaded and the manus begins to align with the direction of flight.

2. The feathering transition phase commences when the inner wing begins to rise and the manus aligns with the flight direction. This phase ends when the manus is fully unloaded and aligned with the alrflow and begins to move rearward as the wing is lifted up and back relative to the body . 
3. The recovery stroke starts at the termination of the feathering transition stage and is the method whereby the wing is brought into position for the next power stroke as rapidiy as possible. The manus is collapsed and moved rearward relative to the body and is hanging almost perpendicular to the inner wing. The inner wing is raised to its highest elevation and at the termination of the recovery phase the manus is ready to be snapped into alignment with the inner wing.

4. The manus-alignment transition phase covers the period between the time where the inner wing has reached its uppermost movement and the beginning of the power stroke. During this phase the manus is snapped into alignment with the inner wing, simultaneously becoming fully loaded. This phase takes place very rapidly. During all phases other than the power stroke, the bird wing is essentially unloaded, except for the inner position of the wing which may maintain a weak aerodynamic load during the feathering, recovery, and alignment phases. The resulting vortex wake produced by the inner wing during these phases would be extremely weak in comparison to the wake produced by the whole wing during the power stroke.

Flapping Wing Vortices

Cone (1968) described the vortex wake of a flapping wing as the periodic aerodynamic forces occuring on the wing during the power stroke. Using a typical Canada Goose 
as an example, in the initiation of the power stroke in fast flight, the wings are raised to approximately $55^{\circ}$ above the horizontal and inclined rearward about $10^{\circ}$ to $20^{\circ}$ from the transverse vertical place. The aerodynamic loading of the wing occurs extremely rapidly; as a result, a definite starting vortex would be shed into the wake. During the wing acceleration, trailing vortices stream from the wing tips with a circulation proportional to the lift on the wing. At the end of the power stroke the wings are angled about $30^{\circ}$ below the horizontal and inclined forward about $10^{\circ}$ to $20^{\circ}$ from the vertical plane. As the outer wing sections decelerate the bound vortex is shed, forming a stopping vortex. Due to the absence of circulation on the outer wing during the feathering transition and recovery strokes, there will be essentially no vortex wake shed during this period.

Figure 9 is a graphic illustration of the vortex wake described by Cone that is shed during the power stroke of a flapping wing. Path $A B$ is the path traced by the center line of the bird and Path $A^{\prime} B^{\prime}$ is traced by a point midway along a semi-span.

Since the geometry and intensity of the flapping wing vortex wake changes periodically during the flapping cycle, a fixed wing vortex analogy superimposed upon this complex system as described by Lissamann and Shollenburger (1971) and Hummel (1973) may result in an inaccurate oversimplification. 
Figure 9. A graphic three-dimensional representation of a complete vortex segment created during a flapping wing power stroke. Path A-B represents the movement of the bird's body. Line $A^{\prime}-B^{\prime}$ represents the path taken by a point midway in the right hand semispan during the power stroke. The cross hatching represents individual transverse and longitudinal vortex filaments. The arrows show the direction of vortex circulation for the starting, stopping and wing tip trailing vortices. 


$$
1
$$


Biot-Sevart Law

It can be noted in Figure 8 that the magnitude of induced drag is directly proportional to the downwash velocity, $D_{1}=\frac{L x W}{v}$. Each component of the vortex wake shed by a formation of birds would induce changes in the downwash velocity for each bird in the formation. If the sum of the vortex induced velocities are opposite to the downwash velocity, the vortex drag will be reduced without any corresponding reduction in 1ift. The Biot-Sevart Law can be used to calculate the resultant of the combined influences of all the vortex segments in a formation of birds on the downwash of any bird in the formation. Figure 10 illustrates how the induced velocity at any point $P$ is calculated as a result of a finite vortex with length $A B$ and circulation $\Gamma$. Quantitative data on the nature of the circulation along the wing of a bird in flapping flight are not available at this time. As a result any investigation of flapping wing aerodynamic properties must be based upon a simplified hypothetical model. 
Figure 10. An 11lustration of the use of the Biot-Sevart equation to calculate the Induced air velocity $v$ at point $p$ as a result of the influence of the vortex segment $A$ B at a distance h and with a circulation of $\Gamma$. 


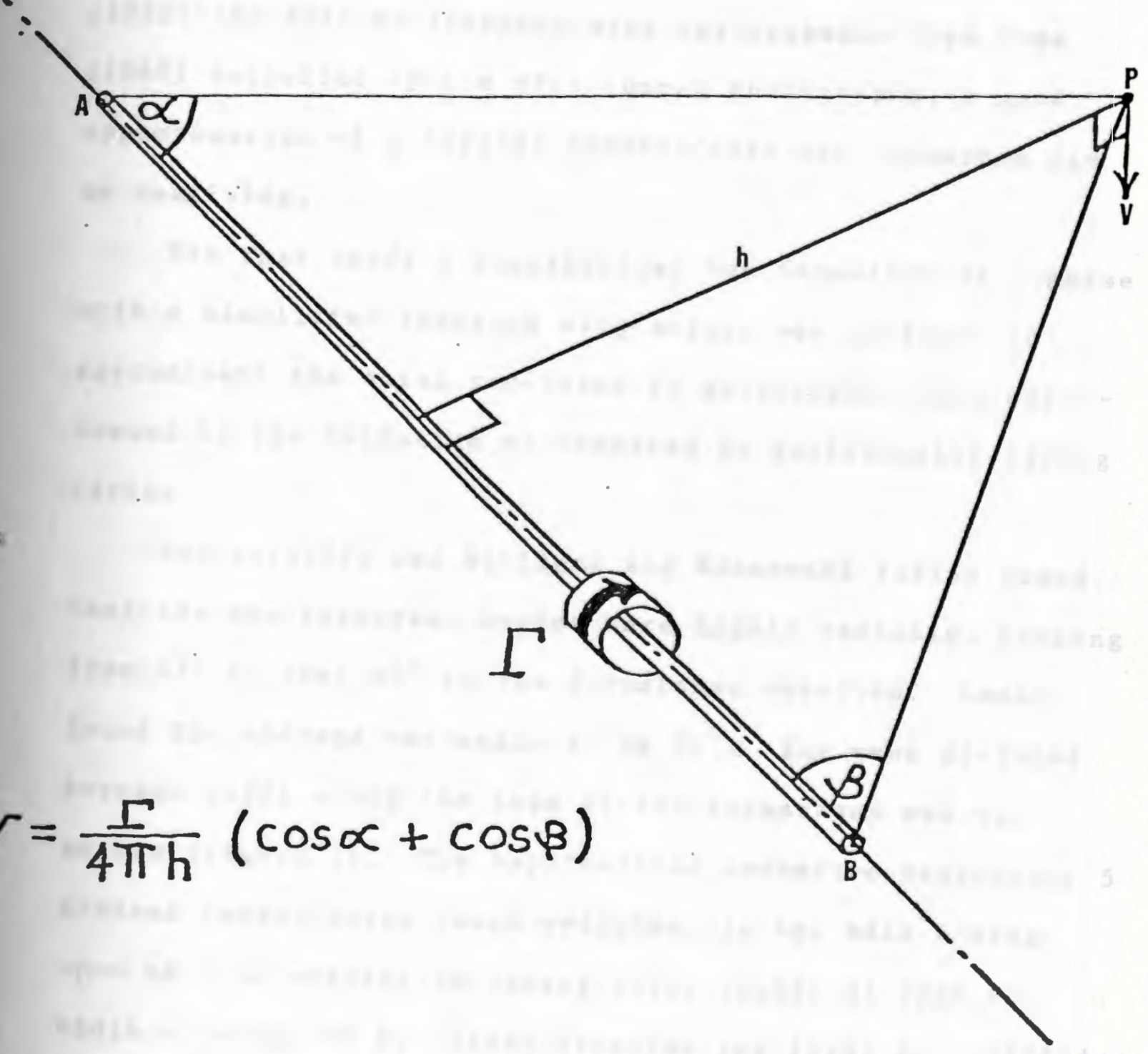




\section{Mode1 Parameters}

With the flight formation geometry data from Gould (1972) and data on flappling wing aerodynamics from Cone (1968) supported by the wind tunnel photographs, a good approximation of a typical Canada Goose vee formation can be described.

For this study a hypothetical vee formation of 5 geese with a simplified flapping wing action was analyzed to approximate the total reduction in aerodynamic drag experlenced by the formation as compared to individually flying birds.

Gould (1972) and Williams and Klonowski (1976) found that the vee formation angles were highly variable, ranging from $27^{\circ}$ to over $90^{\circ}$ in the formations observed. Gould found the average vee angle to be $34^{\circ}$. The mean distance between birds along the legs of the formations was 4.1 meters (Figure 1). The hypothetical formation represents 5 typical Canada Geese, each weighing $3.2 \mathrm{~kg}$. with a wing span of 1.52 meters, an aspect ratio (ratio of span to width of wing) of 6 , flying straight and level at a cruising speed of $54 \mathrm{~km}$. per hour, with an average flapping rate of 4 beats per second. 
The vee formation model proposed in this study is an outgrowth of both vee formation geometry and an adaptation of conventional aerodynamic theory applied to the flapping wing system, resulting in a hybrid semi-rigid theoretical wing system. The following discussion traces the evolution of this model wing system based upon the description of Cone (1968).

To provide adequate simplification for mathematical analysis and yet maintain the basic similarities to the avian flapping wing, an oscllating, flxed wing model was designed for this study. The primary varlations between the model and an actual bird wing are the absence of the rotation of the wing semispans around the humerus joint, and the rigld wing structure of the model.

The omission of the above two factors in the model and their relation to the accuracy of the results will be discussed below.

The theoretical wing model retains the ablifty to imftate the four flapping cycle sequences described above, and produces an equivalent $11 \mathrm{ft}$ at the same average velocity as would an actual flapping goose wing.

The flapping sequence with the hypothetical wing model begins with the power stroke. The entire wing is accelerated downward and forward relative to a flxed point on the body of the bird. It is assumed that the relative wing velocity and average angle of attack of the model wing system are similar to those of an actual flapping wing. At 
the end of the power stroke the wing rotates around 1 ts longltudinal axis to a point where the wing is completely feathered or unloaded and is then recovered to 1 ts starting position, ready to begin a consecutive power stroke. Figure 11 11lustrates the path of the wing from $A^{\prime}$ and $B^{\prime}$ during a power stroke as the model bird moves from point A to B.

On an actual bird, the two semispans are rotated in unison from the humerus joint in a forward and downward direction during the power stroke. The distribution of alr circulation along the wing semispans varies from the base of the wing to the tip as a result of the change in the velocity of the air flow over the wing from base to tip, much like the variation of flow over a rotating propeller blade. The modeled bird wing would theoretically maintain a constant flow over the entire wing, but the total circulation is assumed to remain equal to that of an actual bird พ1ng.

The angle in Figure 11 is assumed to be approximately the same for both the model and the actual bird since it determines the ratio of lift to thrust. The vortex wake produced by the model wing system in straight level flight would appear as a serles equally spaced vortex loops or rectangles of length $A^{\prime} B^{\prime}$ each Inclined at some angle to the horizontal. The velocities induced in the region of a wing by the vortex wakes of other birds in a formation are only effective in reducing the induced drag during the time 
Figure 11. An illustration of the wing action described in the hypothetical flapping wing model. Point A represents the bird center of gravity and point $A^{\prime}$ is in the center of the wing cross section representing the starting position of the hypothetical wing. Points $B$ and $B^{\prime}$ represent respectively the positions of the body center of gravity and the wing cross section after completing a power stroke. The angle $\phi$ represents the inclination of the resultant vortex to the phase of flight. 


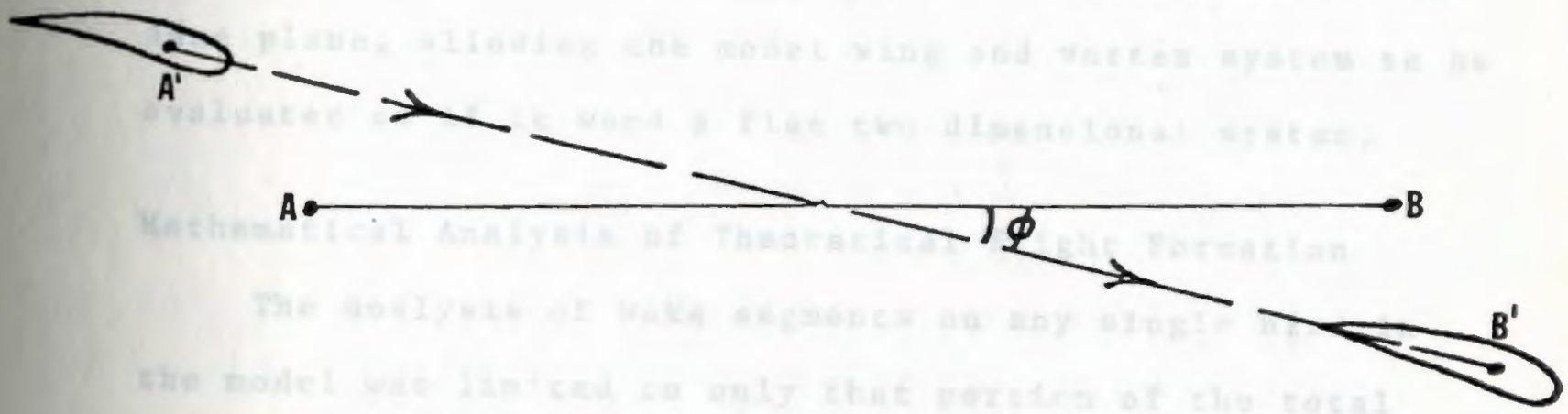


when the wing is producing lift, 1e. during the power stroke. Vortex or 1nduced drag is proportional to the $11 \mathrm{ft}$ produced by a wing, therefore the drag reducing effect of formation flight is beneficial only during the power stroke while the wing is producing ifft. The theoretical wing is always moving parallel to and in the same plane with the vortex wakes of the other birds in the formation during the power stroke. (It is assumed that all birds in the formation move in the same plane.) If the air flow was observed from a reference point on the wing, all air movement and vortex Influence would be experienced in the same plane, allowing the model wing and vortex system to be evaluated as if 1 tere a flat two dimensional system.

Mathematical Analysis of Theoretical Flight Formation

The analysis of wake segments on any single bird in the model was limited to only that portion of the total wake system that produced a change in the downwash velocity of 1 percent or greater. It was further assumed that the wing is elliplcally loaded during the power stroke, so that the value of the downwash remains constant across the span. The analysis of vortex influences on the total formation drag is calculated for each bird, and the totals averaged. It was also assumed that there was no wing beat phase relationship between the birds in the formation.

\section{Model Analysis}

The analysis of the hypothetical formation was 
Table 1 .

\section{Table of Assumptions}

Assumptions for the formation flight model:

1. No vortex wake is shed from the wing during the recovery stroke.

2. The vee formation maintains its geometry.

3. No wing beat phase relationship is maintained within the formation.

4. The wings of each bird in the formation are elliptically loaded during the power stroke.

5. Avian aerodynamics conform to conventional aerodynamic theory and associated physical principles are transferable. 
accomplished in three stages. The first stage sums the Influences of each tralling vortex segment on all birds in the formation.

To obtain the sum of the vortex induced vertical air velocities at each bird in the formation, the Biot-Sevart equation was applied to each trailing vortex segment in the formation. First, the vortex circulation value was calculated from the value of total lift using the equation

1)

$$
\Gamma=\frac{L}{\pi / 4 \rho v b}
$$

This equation gives the circulation value at the center of an elliptically loaded wing. L = total lift which is approximated by dividing the weight of the bird by $\cos \phi$ as shown in Figure 11, and then the result by .54. The later operation increases the lift magnitude to that provided only during the power stroke, since the power stroke lasts an average of 54 percent of the flapping cycle (Cone, 1968). The value of $\rho$ is the density of air at standard temperature and pressure at sea level. $v$ is the velocity of air flowing over the wings and $b$ is the wing span. The circulation as calculated $1 \mathrm{~s} 6.717 \mathrm{~m}^{2} / \mathrm{sec}$. The induced updraft caused by the trailing vortex wake is calculated at a point in the center of each wing in the formation using the Blot-Sevart equations. The downwash velocity for any bird in the formation is approximated by 
Figure 12 diagramatically illustrates the typical measurements needed to calculate the resultant induced velocity at point $p$ on bird $B$ due to the combined influences of trailing vortices 1 and 2 from bird $A$. The rotation of vortex 1 produces a downwash at point p while vortex 2 produces an upwash, so the net influence will be an upwash because of the proximity of vortex 2 to point p.

The second stage in calculating the total drag reduction for a vee formation of geese is to sum the influences of all starting and stopping vortex segments on each bird In the formation. Figure 13 gives a typical example of the method used. The difference between the total induced upwash and downwash for the formation as a whole is used to compute the total drag savings.

After the average reduction in downwash is computed for any bird in the formation, the percent reduction of Induced drag is found by the comparison of Di for a single bird and the mean $D 1$ for a bird in formation.

3)

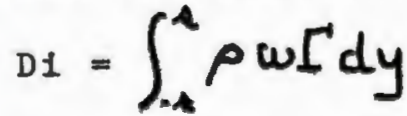

integration results in $D 1=\frac{\pi}{8} P \Gamma^{2}$ (Haughton and Brock, 1960) where $D 1$ is the approximate induced drag for a single bird. The relationship

4) DI $=\frac{L \omega(\text { mean })}{V}$

gives the induced drag for the average bird in the theoretical formation. 
Figure 12. Representation of the method of calculation of the net upwash caused by trailing vortices 1 and 2 from bird A's wing tips on point $p$ at the center of bird B's wing span. Equation a. calculates the effects of vortex 1 , equation b. calculates the effects of vortex 2 , and $c$. represents the net total upwash. 
65

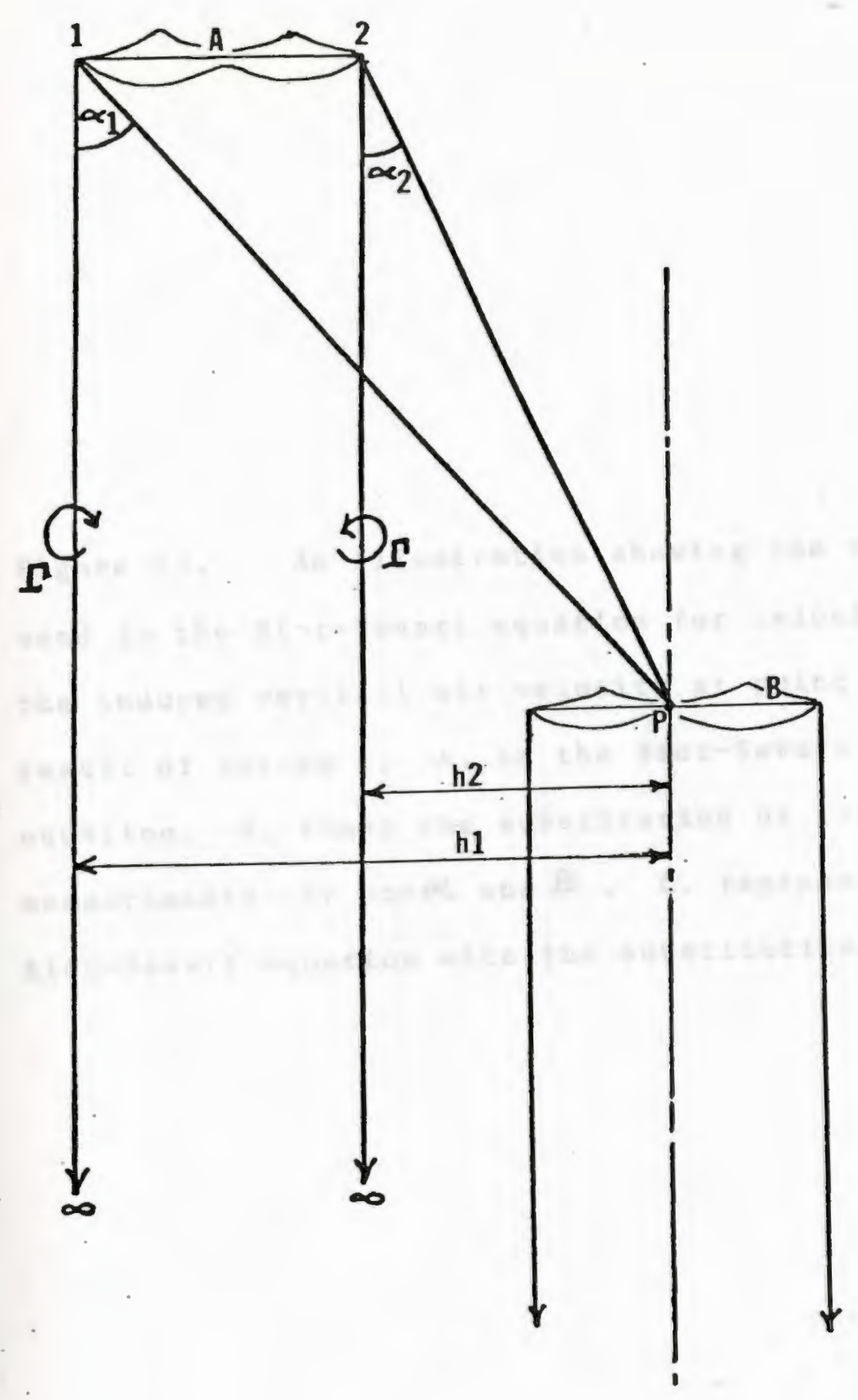

a. $v_{1}=\frac{\Gamma}{4 \pi}\left(\cos \alpha_{1}+1\right)$

b. $v_{2}=\frac{\Gamma}{4 \pi h_{2}}\left(\cos \alpha_{2}+1\right)$

c. $v_{\text {tot. }}=\left(v_{2}-v_{1}\right)$ 
Figure 13. An illustration showing the variables used in the Blot-Sevart equation for calculating the induced vertical air velocity at point $p$ as a result of vortex 1. A. is the Biot-Sevart equation. B. shows the substitution of linear measurements for $\cos \alpha$ and $\beta$. C. represents the Biot-Sevart equation with the substitutions. 
67

a. $V=\frac{\Gamma}{4 \pi h}(\cos \alpha-\cos \beta)$

b. $\cos \alpha=\frac{x}{\sqrt{h^{2}+x^{2}}} \cdot \cos \beta=\frac{-y}{\sqrt{h^{2}+y^{2}}}$

c. $v=\frac{\Gamma}{4 \pi h}\left(\frac{x}{\sqrt{h^{2}+x^{2}}}-\frac{-y}{\sqrt{h^{2}+y^{2}}}\right)$

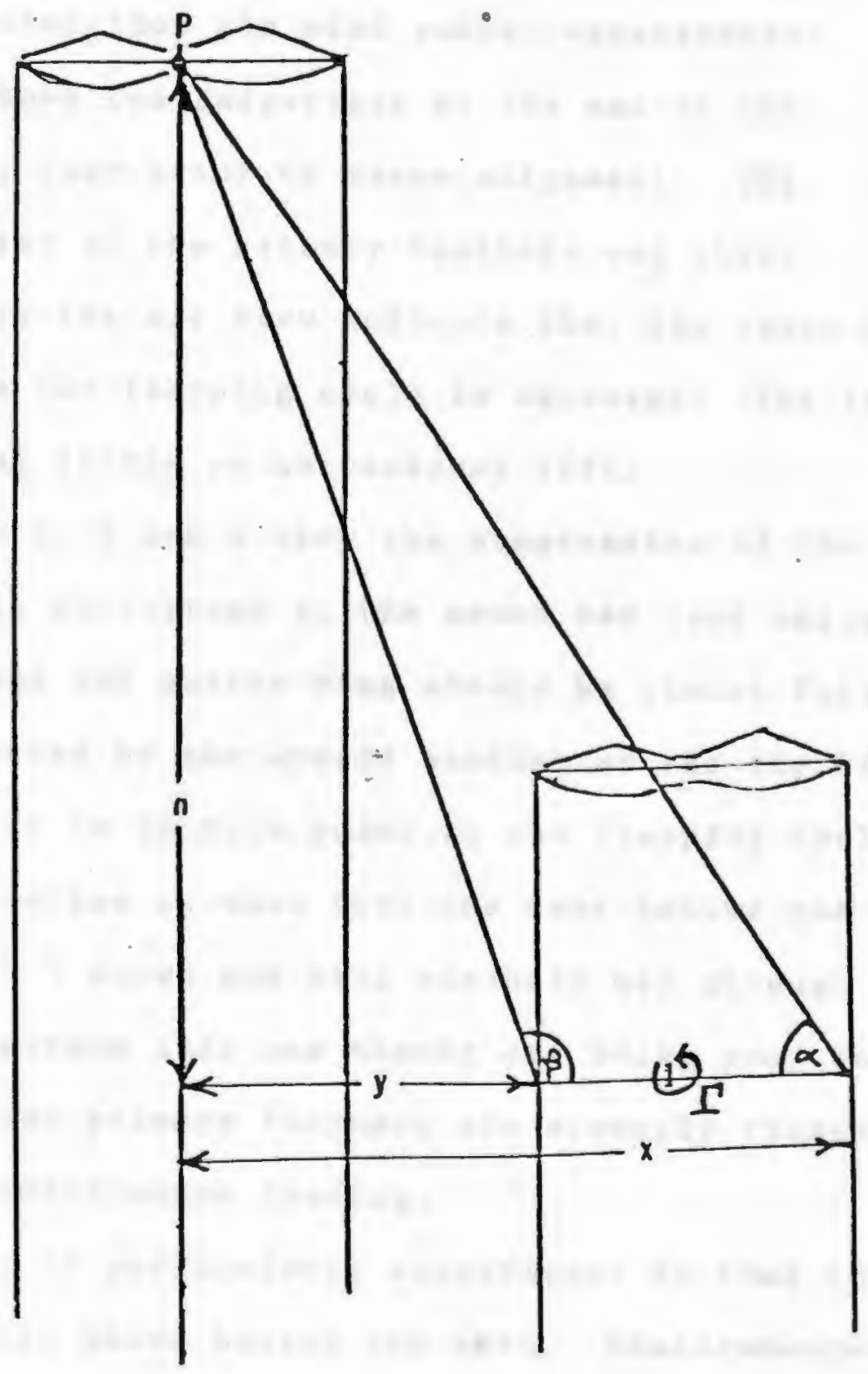




\section{Results}

Wind Tunnel Photographs

Photographs 1-6 on the subsequent pages 111ustrate the results interpreted from the wind tunnel experiments. Photograph \#1 shows the Budgerigar at the end of the recovery stroke, just prior to manus alignment. The unflexed character of the primary feathers and their streamlining with the air flow indicate that the outer wing at this point in the flapping cycle is unloaded. The inner wing is providing little or no residual $11 \mathrm{ft}$.

Photographs 2, 3 and 4 show the progression of the power stroke. In photograph 2, the manus has just snapped into alignment and the entire wing should be almost fully loaded, as indicated by the upward bending at the tip of the primaries. It is at this point in the flapping cycle that a starting vortex is shed into the wake behind the bird. Photograph 3 shows the wing one-half way through the power stroke. Maximum lift and thrust are being produced at this point. The primary feathers are strongly flexed due to the high aerodynamic loading.

Photograph 4 is particularly significant in that the downwash is clearly shown behind the bird. Measurements from the photograph shows the angle to be between $10^{\circ}$ and 
$15^{\circ}$ from horizontal. The downwash 1llustrated in photograph 4 suggests the existance of a rearward Inclined resultant lift vector on a flapping wing during filght. A rearward Inclined lift vector would result from the Influence of a vortex induced drag. The outer portion of the wings at this point are in the process of deceleration and feathering. The bound vortex would be shed into the wake to form the stopping vortex.

Photographs 5 and 6 deplct sequences during the recovery stroke. The feathering transition continues in photograph 5, while the outer wing surfaces begin to trail rearward. In photograph 6, outer wing is completely unloaded and aligned with the alr stream. The inner wing is being raised to begin another power stroke. It can be noticed that there is no observable angle of attack on the inner, Indicating little or no lift is being produced.

The results of the mathematical analysis of the vee formation model are tabulated on Table 2. The letters in column 1 refer to the relative positions of the birds as shown in Figure 1. For example: the first entry refers to originating bird $A$ as the bird producing the vortices and bird $B$ as the bird experiencing the effect of the vortices. Column 3 of the first entry shows the total updraft velocity experienced by bird $B$ as a result of the wing tip vortices from bird A. Column 4 indicates that in the five bird formation this type of influence occurs on four separate occasions. Bird A's effect on B. Bird B on 
bird D. Bird A on bird $C$ and bird $C$ on bird D. The last column corrects the value shown in column 3 to reflect the Intermittant nature of the vortex wake. (The vortex is only present 54 percent of the time.) Each succeeding entry shows the values calculated using the Blot-Sevart equations for each type of Influence situation within the formation.

The mean updraft value for a bird in the formation is calculated by multiplying column 4 times column 5 and calculating the mean value of all influences. The average updraft experienced by a bird in the hypothetical formation is $0.078 \mathrm{~m} / \mathrm{sec}$. The downwash value for a hypothetical bird In solitary flight is calculated using equation 2 , and is $0.671 \mathrm{~m} / \mathrm{sec}$. The average percent reduction in downwash for any bird in the formation is: mean formation updraft/ solitary bird downdraft $x 100=11.6$ percent reduction in downdraft velocity for the formation. Since downdraft velocity and Induced drag are directly proportional an 11.6 percent decrease in induced drag is realized by the formation as a whole. 


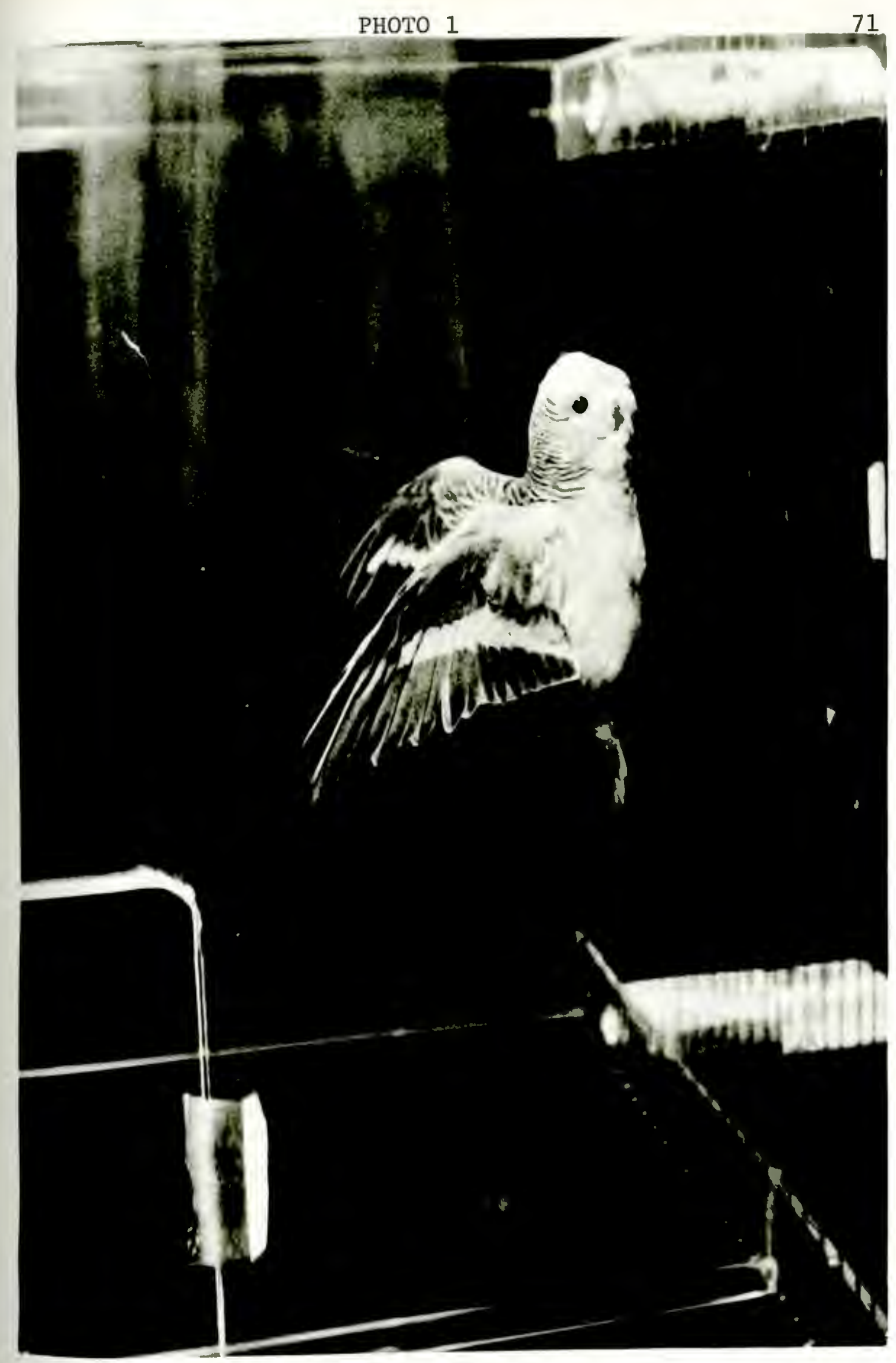


PHOTO 2

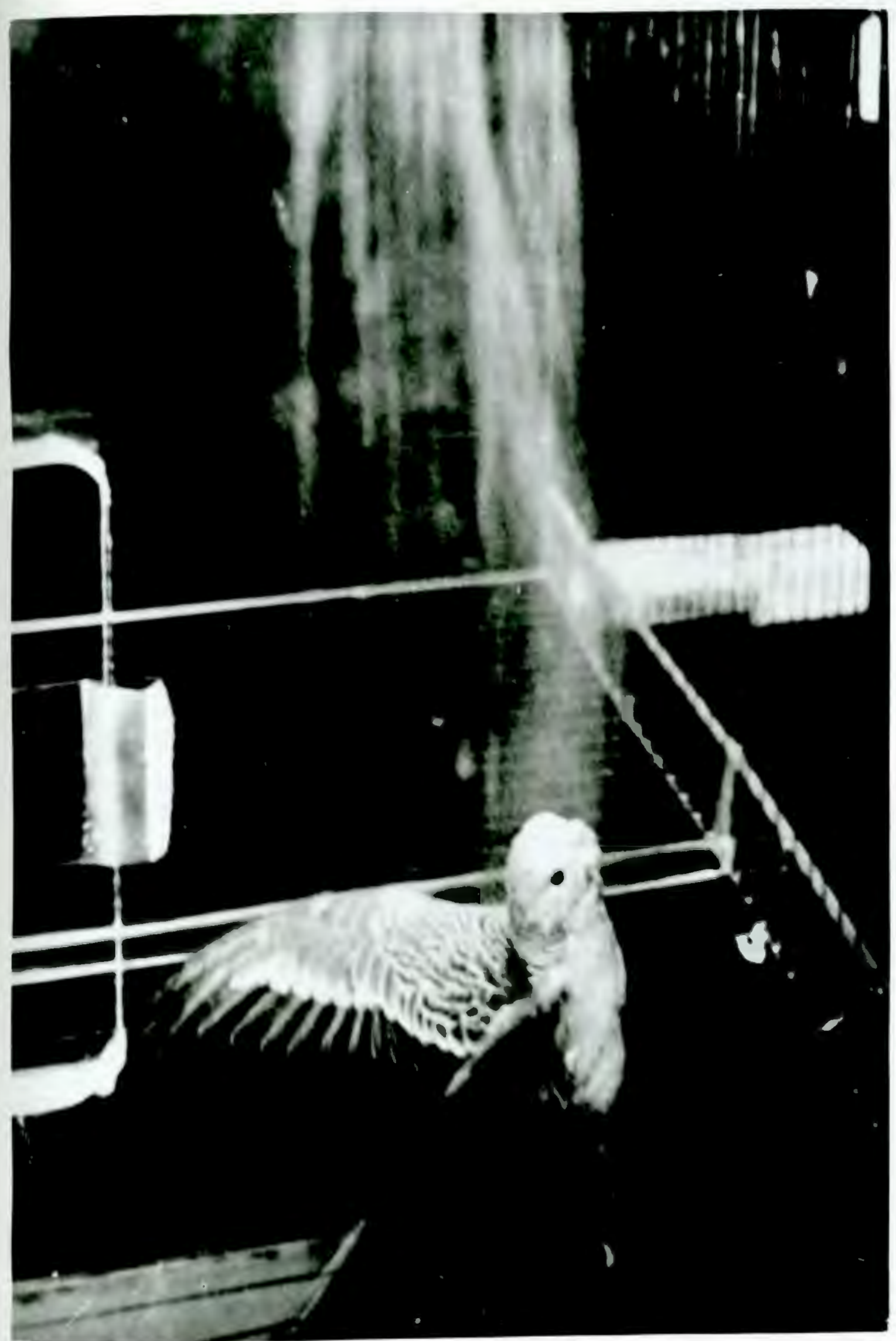


PHOTO 3

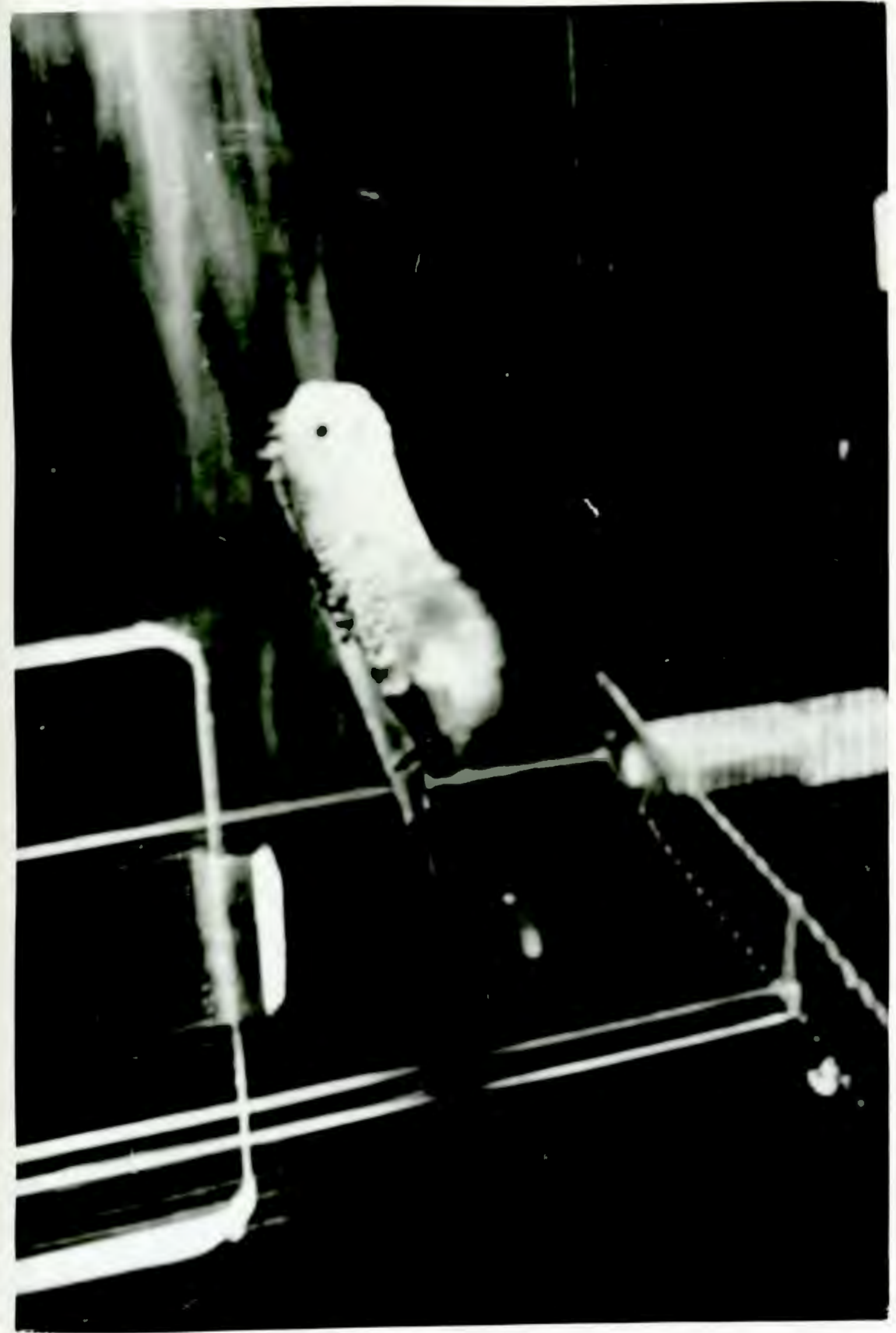




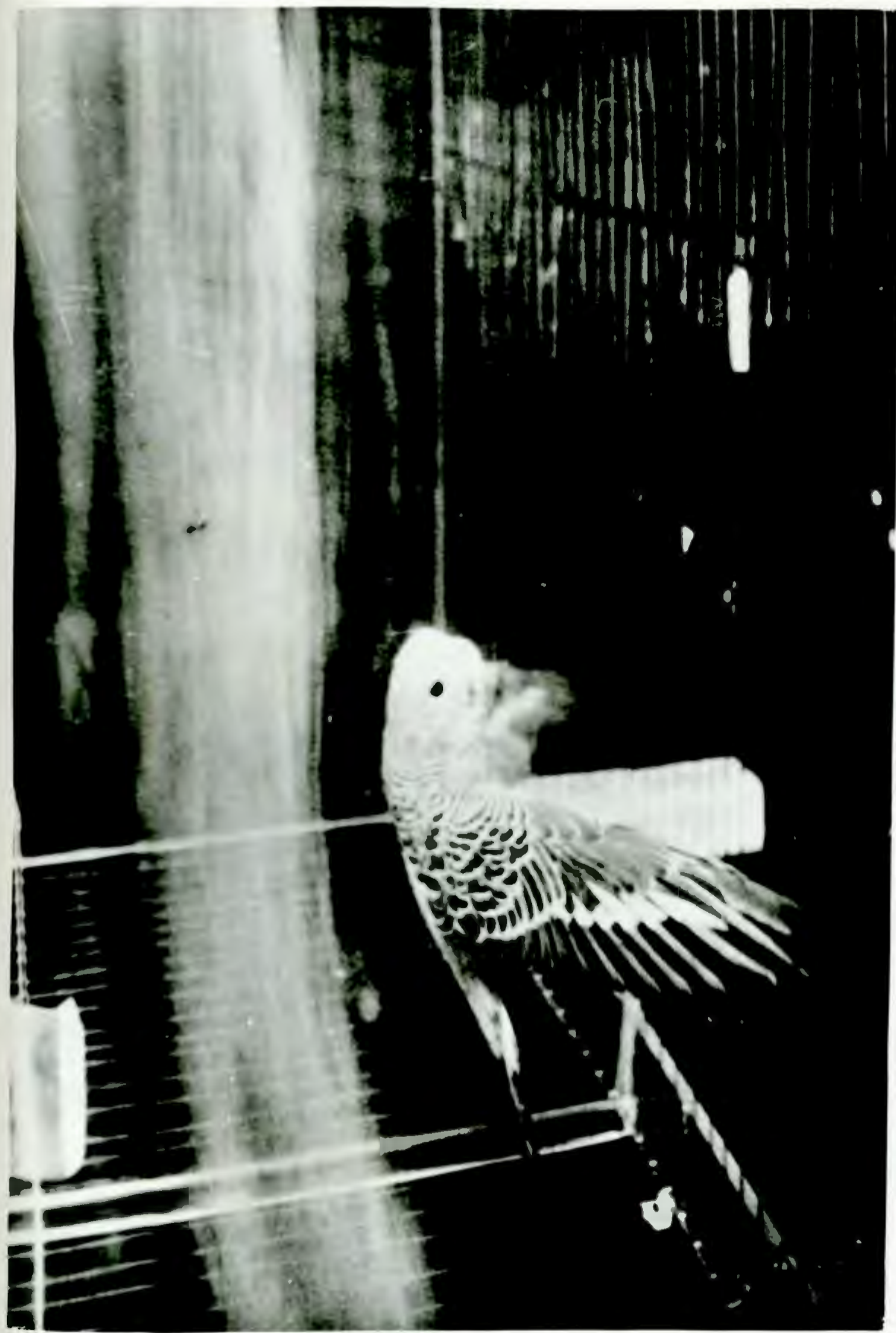



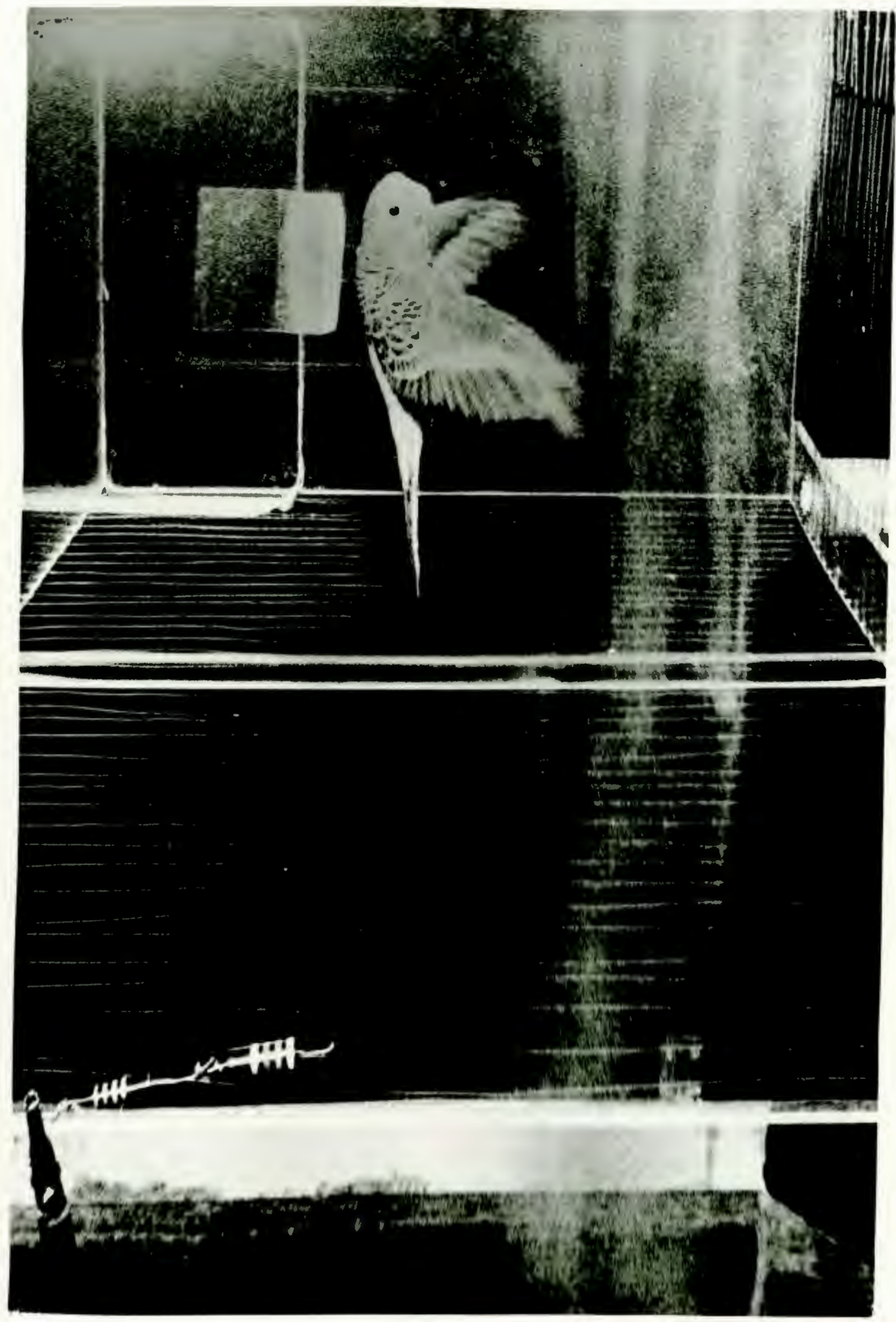


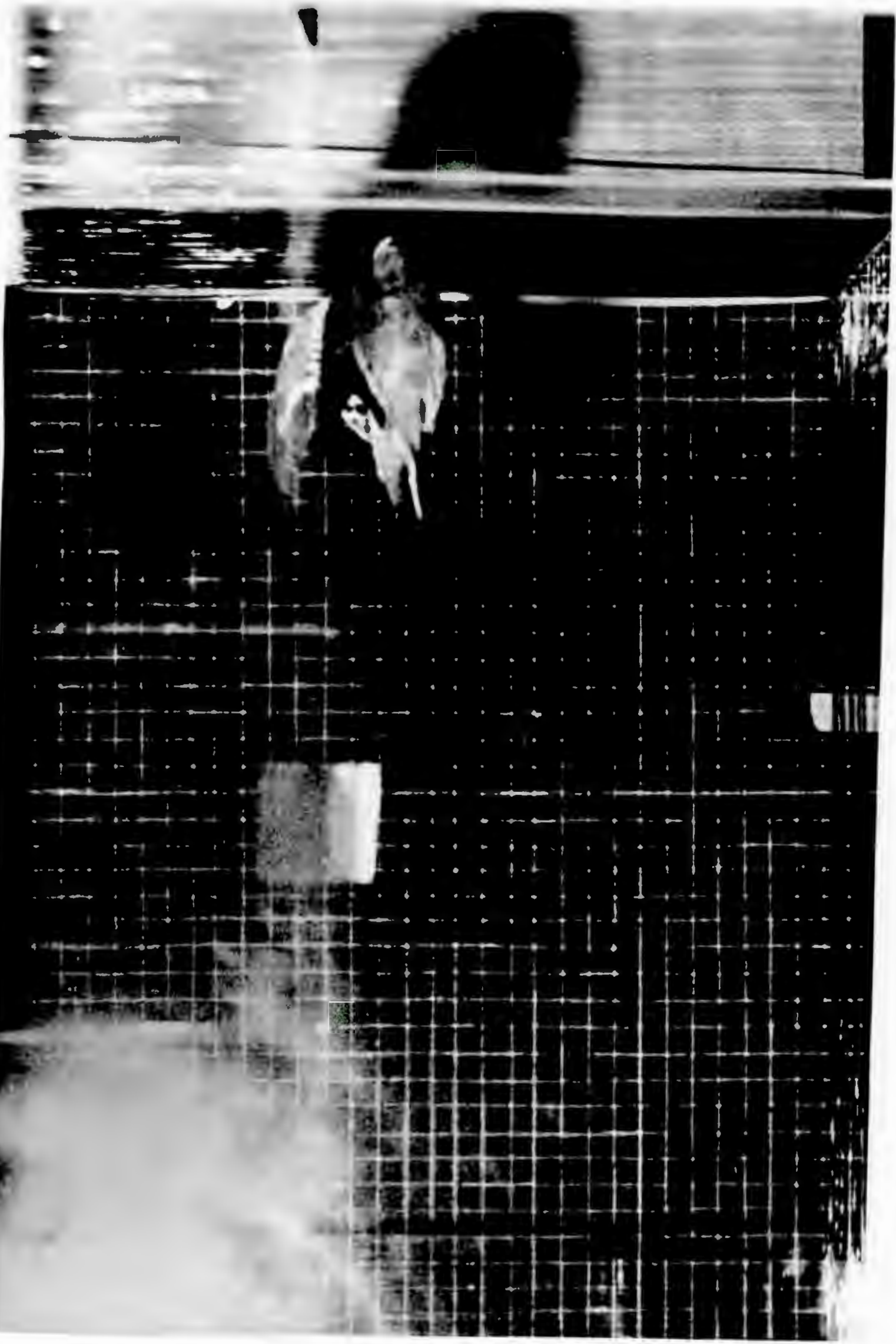


Table 2

Calculated Updraft Values Due to Vortes Wake Effects on Birds In Vee Formation (Refer to Figure 1)

1

2

3

4

5

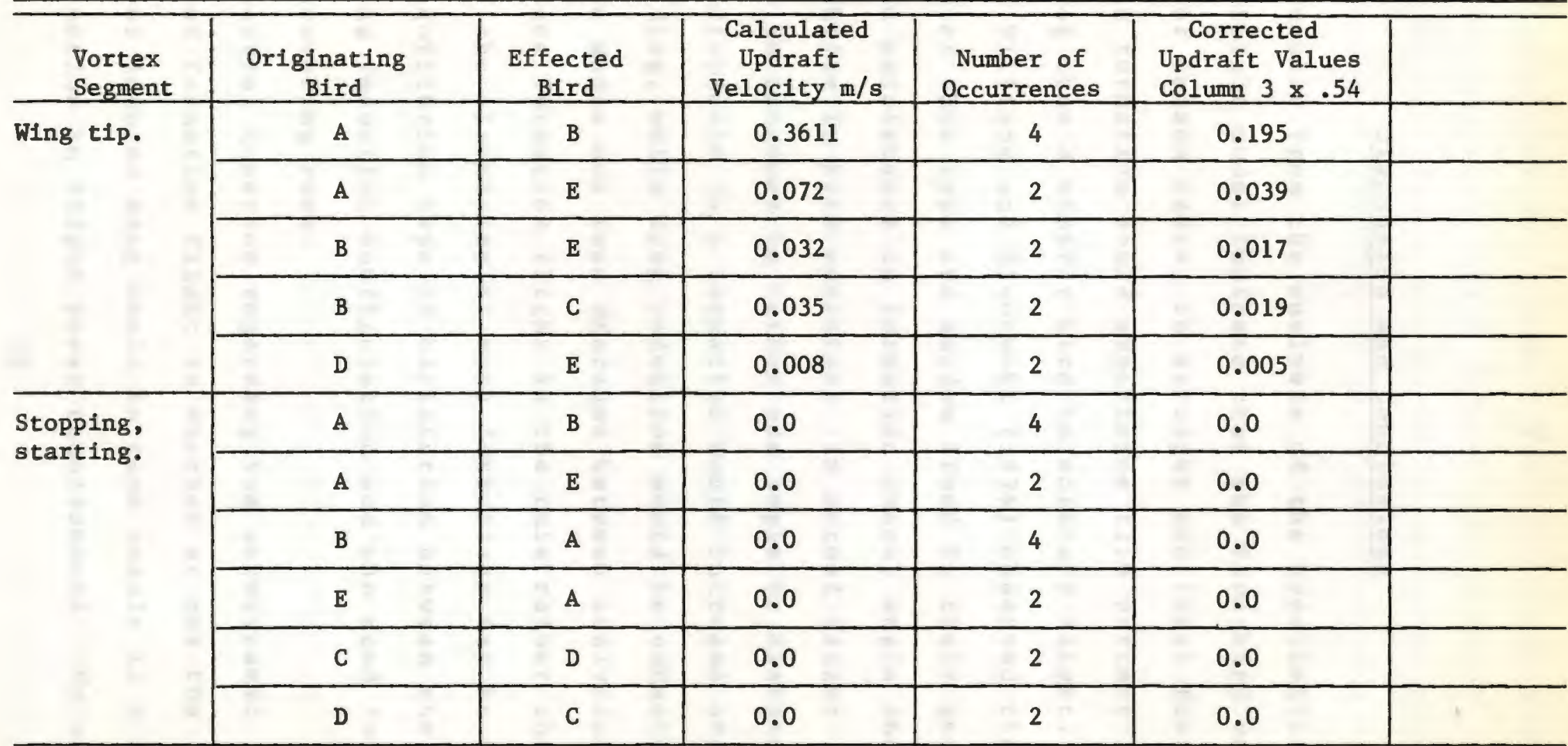

Mean updraft for bird in formation. $0.078 \mathrm{~m} / \mathrm{sec}$. Downwash for bird in formation. $0.591 \mathrm{~m} / \mathrm{sec}$.
Solitary bird downwash. $0.671 \mathrm{~m} / \mathrm{sec}$. Percent reduction of $\mathrm{DI}$ "for bird in formation. 11.6 


\section{Discussion and Conclusions}

The results from the analysis of the hypothetical formation flight model indicate that the five-bird vee formation of Canada Geese, In straight and level fast flight, the formation would experience 11.6 percent less induced drag than a similar bird in solitary filght. Gould (1972) and W1111ams and Klonowskl (1976) observed that formations of this type are seldom fixed in their geometry, with little persistance in formation shape, angle and with constant shifts in bird position. In actual filght formations an increase in either vee angle or distance between individuals in a formation would increase overall formation drag, while drag reduction would be enhanced by a smaller vee angle and less distance between individual birds. Since formation flight is the rule rather than the exception, the elasticity of such formations may be assumed to be an equilibrium type of oscillation between the optimum drag reduction configuration and the need for flight maneuvering room.

The central question regarding the aerodynamic advantage of formation flight is whether or not the reduction of induced drag would in turn result in a significant reduction in flight power requirements. My analysis 
suggests that it may not. Cone (1968) stated that induced drag was the most significant portion of the total aerodynamic drag experienced by a bird in flapping flight, and therefore the most significant in terms of the total portion of energy used to overcome its effect. The model used in this study to calculate the vortex drag reduction was, for the purpose of necessary simplification, an oscillating rigid wing. The results are therefore based on a non-flexible wing structure. Cone's analysis of induced drag produced by the elastic bird wing indicates a relatively high aerodynamic efficiency for the flapping wing, which in all probability is considerably more efficient than a fixed wing of the same span, traveling at the same body speed and producing the same $11 \mathrm{ft}$. Cone 11 sts and discusses five factors associated with the flapping wing, which contribute to the reduction of the induced drag. 1. Reduction in starting and stopping drags. The starting drag can be reduced due to the proximity of the wings at the beginning of the power stroke, which results in the partial reduction of the starting vortex of each semispan. The starting vortices of each semispan are mirror images of each other and therefore cancel each other when in close proximity. Stopping drag is lessened by the updraft created in the wing vicinity by the shed stopping vortex, as the wing decelerates. 2. The curved vortex sheet wake lengthens the distance between the vortex wake elements and the wing, reducing the induced velocities at the wing. 
3. The relatively high aerodynamic velocity of the wing during the power stroke produced a given lift with a low wing circulation value, and hence a low induced drag.

4. The spreading and flexing of the pinion feathers diminishes the local intensity of the vortex by spreading it over a wider area. 5. The unloading of the outer wing during the recovery stroke eliminates their vortex induced drag during part of the flapping cycle.

The aerodynamic model proposed in this study was designed to conform as closely as possible with the mathematical flapping wing model of Cone (1968). The model is capable of reproducing three of the five drag reducing factors mentioned by Cone, but only two are included in this study. The curved vortex sheet wake factor, and the flexability of the wing structure and the reduction of starting and stopping vortex drags could be included in the calculation of the induced drag produced by the model, but the mathematics involved are beyond the scope of this study. The high aerodynamic velocity of the wing during the power stroke was included in the analysis, as was the unloading of the outer wing during the recovery stroke.

Until sufficient data become available, the actual values for the induced drag of a flapping wing cannot be obtained. One of the objectives of this study was to Investigate means by which such data could be obtained. By the utilization of a combination of techniques such as air flow visualization, high speed photography, and wind tunnel 
analysis, a satisfactory method could be worked out to obtain the needed data. One such procedure would Involve the measurement of vortex circulation using air flow visualization In a wind tunnel. ThIs study found that the use of smoke streams as described by Brown (1952) was unsatisfactory for all but the most general observation of flow direction. Because of the nebulus character of the smoke, it was not possible to determine the speed and direction of the alr flow around discreet sections of the wing. The air flow indicator must be resolvable into individual particles so that their speed and direction could be tracked. Small solid or bubble-like particles of known mass and aerodynamic characteristics could be injected upstream of a bird flying in the test section of the tunnel. The progress of individual particles could be tracked by the use of dual stroboscoplcally controlled narrow focal plane cameras mounted to photograph vertically and horizontally. The Intersection of the focal planes would provide a small area of known coordinates through which the particle could be tracked. Analysis of sets of photographs would provide direction and speed data of selected alr flows over the wing and in the wake. Circulation and downwash velocity values could be obtained by this method. The metabolism of the bird could be determined by the method described by Tucker (1968). The average updraft for a formation of birds would be calculated using the wind tunnel data and the Blot-Sevart 
equations. To obtain the energy savings for a formation of birds an artificial updraft could be produced in the tunnel by elther injecting a vertical air flow, or tilting the tunnel until the vertical component of the alrflow matches the value of the Induced updraft velocity. Measurement of the metabolism of the bird flying in the adjusted environment would provide a comparison of flight energy requirements of a bird in solitary flight as opposed to formation filght.

Another method of measuring the aerodynamic characteristics of the avian wing during flapping flight would be to utilize a modification of the laser anemometry techniques described In Appendix A. Laser anemometry was developed for the National Aeronautics and Space Administration to detect afr turbulence and was intended for use at alrports to measure and track trailing vortexes. It is a laserDoppler system that measures afr movement by computer analysis of laser light reflected from atmospheric dust particles, and can be modified to measure alr flow around subjects in wind tunnels.

In normal use the laser intensities would be too strong for animal subjects. However, if the distances between the laser source and the subject were kept to 45 cm. or less, a low power helium-neon laser could be used in conjunction with a photon-correlation signal processing method to eliminate the danger of burning the test animal. (Robert E. Bower, pers. comm.) 
Laser anemometry appears to be the most promising method of analysing the air flow around live wind tunnel subjects since it exerts no external influence on the test subject. Drawbacks of system complexity and cost would restrict 1 ts use as a universal research tool.

In their analysis of the aerodynamic advantages of formation flight, Lissaman and Shollenberger (1970) found that a vee formation of birds had approximately 71 percent more range than a single bird. If this figure is interpreted as a measurement of energy savings, it represents a much greater saving than that predicted in my study. Lissaman and Shollenberger considered the bird to be a fixed wing vehicle of the same geometry. When Lissaman and Shollenberger's fixed wing analogy was applied to the model structure used in this study, a total induced drag reduction of only 21.5 percent was calculated for the model five bird formation. The 21.5 percent reduction was calculated using the uncorrected downwash values as shown in column 3 of Table 2 . These values represent the Influences of a continuous vortex wake as would be present behind a fixed wing traveling at a constant speed. The mean updraft value for a formation would be $.145 \mathrm{~m} / \mathrm{sec}$. Reduction In Induced drag would be $.145 \mathrm{~m} / \mathrm{sec} . / .671 \mathrm{~m} / \mathrm{sec} . \times 100=21.5$ percent. Since IIssaman and Shollenberger did not state their method of calculating the drag reduction, the differences in their results and the results of this study cannot be reconciled at this time. In steady-state fixed wing 
flight, thrust must equal drag, so the 21.5 percent reduction in drag would convert directly to a similar savings in flight energy requirements or an extension of flight range. In flapping flight, excess thrust is produced during the power stroke to accelerate the bird forward. The excess thrust makes it difficult to determine, in the absence of experimental data, the proportion of the total flight energy needed to overcome the induced drag created during the power stroke.

Lissaman and Shollenberger's (1970) paper does not take into account the fact that a flapping wing produces both lift and thrust simultaneously. Instead they treat the avian wing as if it were only producing lift, which may account for the difference in their predictions as compared to those of my study. Considering the dissimilarities between flapping bird flight and flxed wing flight, as mentioned earlier in this paper, the use of a fixed wing analogy for formation flight analysis in birds may represent an oversimplification.

In his paper on the power reduction in formation flight, Hummel (1973), to the contrary, stated that the fixed wing is an adequate simplification for the flapping wing. Lissaman and Shollenberger (1970) assumed that fixed wing and flapping wing flight are similar in power requirements, and therefore must be similar aerodynam1cally. Hummel (1973) acknowledged some aerodynamic disparency between the two flight modes. He, however, 
reconciled these differences by assuming that a full aerodynamic load is carried by the inner portion of the wings during the recovery stroke, so that the mean $11 \mathrm{ft}$ distribution over the entire wing remains fairly constant. This view is opposite to arguments put forth in my study and that of Cone (1968), and would result In unnecessary energy consumption while reducing the overall efficiency of the power stroke.

Although several authors suggest that a substantial amount of lift is maintained by the Inner wing during the recovery stroke (Humme1, 1973; Brown, 1952), the opposite situation would provide the most advantageous conditions for flapping flight. It would seem logical that lift be kept to an absolute minimum during the recovery stroke for the following reasons. To conserve flight energy it would be advantageous to allow the wing to return passively to its starting position. This could be done by allowing the center of gravity of the body to drop as the wings are raised. This type of action has been observed in Buderigars flying in the wind tunnel and the author has observed the behavior in Herring Gulls flylng close alongside a boat. As a result of this type of flight behavior, the Inner wing would become partially or completely unloaded. The second reason for maintalning reduced lift on the inner wing would be to keep drag to a minimum. To Increase the effectiveness of the subsequent power strokes, the majority of the forward velocity of the bird must be 
maintained along with a minimum of altitude loss. The drag created by an active recovery stroke would reduce the efficiency of the subsequent power stroke. Two possible modes of flight are available to the bird during the recovery stroke sequence. The first is described above as a passive recovery of the wing structure in preparation for the next power stroke. In this mode very little lift is produced, and therefore only a small amount of drag. The second mode would be an active recovery stroke which would generate enough lift to maintain the bird at the same altitude. Hummel (1972) subscribes to this method of wing recovery with the inner wing carrying the total aerodynamic 1oad. If this were the case the increased angle of attack necessary would produce a backward tilting lift vector, which would result in a negative thrust or drag that would tend to nullify any beneflt the extra energy expenditure during the recovery stroke might provide. (Figure 14)

As shown in Table 2, the wing tip vortex wake elements are the only part of the wake system that creates a net upwash In the formation. The transverse stopping and starting wake segments shed perlodically by the bird wing during flapping flight produce no net influence on the formation. They are equal in circulation, but opposite in rotation, and thereby cancel each others influence.

It has been reported that a wing beat phase relationship is necessary in order for formation flight to provide an aerodynamic advantage (Geyr von Schweppenburg, 1952 ; 
Nachtigall, 1970). The analysis done in this study was based upon the assumption that there was no wing beat phase relationship operating in the formation. The results indicate that in spite of this condition an 11.6 percent reduction in induced drag could be realized.

If Nachtigall's (1970) data are correct, induced formation drag would be further reduced from that shown above. The increased drag reduction attainable if a wing beat phase relationship existed in the formation would result from the fact that each bird would adjust its flapping rate to ensure that each power stroke occurred just as vortex wake segment of the bird ahead was at 1 ts closest proximity. Since conflicting data exist concerning wing beat relationships, a careful study of the analysis techniques used in previous studies and of formation flight photographs may resolve the question. It is interesting to note that data used for the flight formation geometry in this study, which represent the mean formation angle and bird separation distances of the vee formations observed by Gould (1972), favor the adoption of a wing beat phase relationship. At a flight speed of 15 meters per second the distance each bird covers during a single flapping cycle is almost exactly the distance between consecutive birds along the arms of the vee formation. Each bird is one flapping cycle apart. This would indicate that if a phase relationship was operating within a formation, the 
phase would be $180^{\circ}$ between adjacent birds in an average formation.

The hypothetical flapping flight model presented in this study is an attempt to refine to the next level of sophistication the formation flight models presented by the authors of the papers discussed above. It still only crudely approximates the extremely complicated aerodynamic processes occurring during actual flapping formation flight. Immediate enhancement of the models' effectiveness could be gained by including the effects of the curved vortex wake segments.

The most significant feature of the flapping wing in the character of the vortex wake is the effect of the pinion feathers. Cone (1968) described the Influence of the pinions as the most significant factor in the reduction of Induced aerodynamic drag. Accurate modeling of their Influence must wait until more experimental data is avallable.

Although previous studies and this one have demonstrated that definite aerodynamic advantages are avallable to birds in vee formation flight, the significance that this advantage has on the energy requirements during long migratory flights has not been determined. Future studies In this area should address themselves not only to the aerodynamic characteristics of the flapping wing, but also to the flight energy requirements of fast flying waterfowl such as the Canada Goose. Investigation of flight 
Figure 14. Profile wing sections illustrating the lift drag and thrust vectors:

a. total lift

b. resultant $11 \mathrm{ft}$

c. thrust or drag

d. wing movement

e. bird movement

1. Power stroke.

2. Theoretical active recovery stroke. 

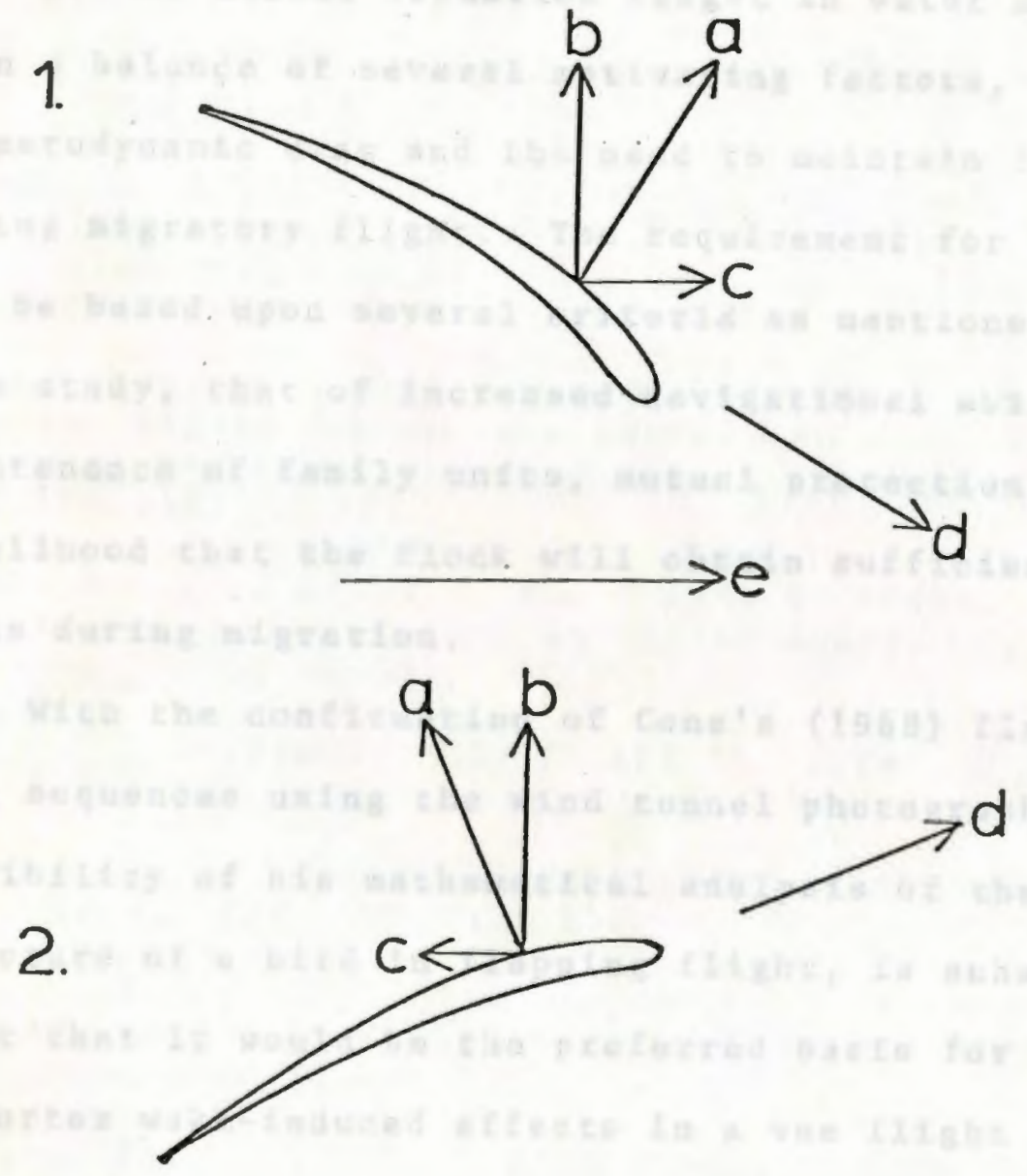
formation geometry has been done by Gould (1972) and W1111ams and Klonowsk1 (1976), however more extensive observation of formation flight is needed to confirm the data and to provide additional data on both the horizontal and vertical distribution of birds within formations.

The most supportable hypothesis concerning the function of linear formation flight in water birds is based upon a balance of several motivating factors, the reduction of aerodynamic drag and the need to maintain flock unity during migratory flight. The requirement for flock unity may be based upon several criteria as mentioned earlier in this study, that of increased navigational ability, maintenance of family units, mutual protection, increased likelihood that the flock will obtain sufficient feeding areas during migration.

With the confirmation of Cone's (1968) flapping flight wing sequences using the wind tunnel photographs, the credibility of his mathematical analysis of the vortex wake structure of a bird in flapping flight, is enhanced to the point that it would be the preferred basis for an analysis of vortex wake-1nduced effects in a vee flight formation of Canada Geese. 


\section{Literature Cited}

Austin, 0. L. (1961). Water and Marsh Birds of the Wor 1d. New York: Golden Press.

Beer, J. R. (1958). The composition of bird flocks. F11cker. $30,78-83$.

Bent, A. C. (1925). Life Histories of North American Waterfow1. Pt. 2. New York: Dover Publ.

Berger, M. (1972). Formationsflug ohne Phasenbeztehung der flugelschlage (Formation Flight Without Phase

Relationship of Wing Beats). J. Ornitho1. 113, 161169 .

Brown, F. N. M. (1952). The visible wind. Proceedings of the Second Mid-western Conference on Fluid Mechanics, Ohio State Unfversity Studies Englneer1ng Serles. 21 , $119-130$.

Brown, R. H. J. (1953). The flight of birds. II. Wing function in relation to flight speed. J. of Exp. B101. $30,90-103$.

$460-489$.

(1963). The flight of birds. B101. Rev. 38,

Col11as, N. E. (1952). Development of social behavior In birds. Auk. 69, 127-157.

Cone, C. D. (1968). The Aerodynamles of Flapping Bird Flight. Virginia Institute of Marine Science Special Sclentific Report 52 .

Darling, F. F. (1938). B1rd Flocks and the Breeding Cyc1e. Cambridge: Cambridge University Press.

- (1952). Social behavior and survival. Auk. $69,183-191$.

Davis, W. M. (1896). The soaring of birds on currents of a1r. Auk. 13, 92 . 
Delacour, J. and E. Mayr. (1945). The family Anatidae. Wilson Bu11. $57,3-55$.

Dwinne11, J. H. (1949). Princlples of Aerodynamics. New York: McGraw-H111.

Elder, W. H. and N. L. Elder. (1949). Role of the family in the formation of goose flocks. W11son Bul1. 61, 133-140.

Eliassen, E. (1963). Preliminary results from new methods of investigation of physlology of birds during filght. Ib1s. 105, 234-237.

Emlen, J. T. (1952). Flocklng behavior in birds. Auk. $69,160-170$.

Feldmann, I. F. (1944). Windkanaluntersuchung am Modell elner Mowe. Aerorevue. 19, 219-222.

Forbush, E. H. (1912). A History of the Game Birds, Waterfow 1 , and Shore Birds of Massachusetts and Adjacent States. Massachusetts State Board of Agriculture. Boston: Wright and Pottor Co.

Franzisket, L. (1951). Uber die Ursachen des Formationsfluges. Vogelwarte. 16, 48-55.

George, J. C. and A. J. Berger. (1966). Avian Myology. New York: Academic Press.

Geyr von Schweppenburg, H. (1952). Vortelle der Zuggeselligke1t. Vogelwarte. 16, 116-119.

Gould, L. L. (1972). Formation flight in the Canada Goose, (Branta C. Canadens1s) M. S. Thes1s, Univ. Rhode Is land.

Greenewa1t, C. H. (1960). The Wings of Insects and Birds as Mechanical Oscillators. Proc. Amer. Phil. Soc. $104,605-611$.

- (1962). Dimensional Relationships of Flying AnImais. Smithson. Misc. Collns. 144, 1-46.

Hamilton, W. J., III. (1967). Soclal Aspects of Bird Orientation Mechanism. Animal Orientation and Navigation. (R. M. Storm, ed.) Oregon State Univ. Press. Corva111s.

Hanson, H. C. (1965). The Glant Canada Goose. I11inois: Southern IIIInols Univ. Press. 
Heppner, F. H. (1974). Avian flight formations. Bird Banding. $45,160-169$.

Houghton, E. L. and A. E. Brock. (1960). Aerodynamics for Engineering Students. London: Edward Arnold Ltd.

Humme1, D. (1973). Die Leistungsersparnis biem

Verbandsflug (The Power Reduction In Flight Formations). J. Ornithol. 114, 159-282.

Keeton, W. T. (1971). Magnets interfere with pigeon homing. Proc. Nat. Acad. Sci. 68, 102-106.

King, J. R. and D. S. Farner. (1965). Studies of fat deposition in migratory birds. Annals. N. Y.Acad. Sc1. $131,422-440$.

Le Page, W. L. (1923). Wind channel experiments on a Parlah Kite. Royal Aeron. Soc. London. 27, 114-115.

Lissaman, P. B. S. and C. A. Shollenberger. (1970). Formation flight of birds. Science. 168, 1003-1005.

Lorenz, K. Z. (1937). The companion in the bird's world. Auk. 54, 245-273.

McGahan, J. (1973). Flapping flight of the andean condor In nature. J. Exp. B101. 58, 239-253.

Munk, M. M. (1933). The Princlples of Aerodynamics. New York: The Ronald Press Company.

Nachtiga11, W. (1970). Phasenbezlehungen der

flugelschlage von Gansen wahrend des Verbandflugs in Keilformation. (Phase Relationship in the Wing Beat of Geese Flying in Vee Formation.) Z. vergl. Physiologie. $67,414-422$.

Nisbet, I. C. T. (1963). Welght-loss during migration. Part II: Review of other estimates. Bird Banding. $34,139-159$.

(1967). Aerodynamic theories of flight versus physiological theories. Bird Banding. 38, 306-316.

Parkinson, I. R. (1944). Aerodynamics. New York: The MacMillan Company.

Parrott, G. C. (1970). Aerodynamics of gliding flight of a black vulture, Coragyps atratus. J. of Exp. Biol. 53, 363-374.

Pennyculck, C. H. (1969). The mechanlcs of bird migration. Ib1s. 111, 525-556. 
Phillips, J. C. (1910). Notes on the autumn migration of the Canada Goose in eastern Massachusetts. Auk. 27 , 263-271.

Poncy, R. (1941). Formations Angulares des vols de quelques especes d'Oiseaux migrateurs et les reactions observees (particulierement chez les Canards.).

(Angular Formations of the Flight of Some species of Migrating Birds and the Observed Reactions (Particularly Among Ducks)). Ornithol. Beob. 1, 17-18.

Preston, J. W. (1892). Notes on Bird Flight. Ornithologist and 0ologist. 41-42.

Queeny, E. M. (1947). Prairie Wings. New York: J. B. Lippincott.

Raspet, A. (1950). Performance measurements of a soaring bird. Aeronaut. Engineer. Rev. 9, 14-17.

$132,191-200$.

(1960). Biophysics of bird flight. Science.

Raveling, P. G. and E. A. LeFebvre. (1967). Energy metabolism and theoretical flight range of birds. Bird Banding. $38,97-113$.

Ruthven, J. A. and W. Zimmerman. (1965). Top Flight:

Speed Index to Waterfowl of North America. Milwaukee: Moebius Printing Company.

Savile, D. B. 0. (1957). Adaptive Evolution in the Avian Wing. Evolution. 11, 212-224.

Schaefer, G. W. (1968). Energy requirements of migratory f1ight. Ib1s. 110, 413-414.

Schnitzler, H. U. (1972). Windkanalversuche zur

Abhangigkelt der Fluggeschwindigkelt einer Weifschelte lammer (Zonotrichia leucophrys) von der

Windeschwindigke1t. (Flight Speed of a White-Crowned Sparrow In a Wind Tunnel at Different Wind Speeds.) J. Ornithol. 113, 161-169.

Storer, J.H. (1948). The F11ght of Birds. Cranbrook Inst. of Sclence Buliet1n No. 48. MIchigan: Cranbrook Press.

Terres, J. K. (1968). Flashing Wings: The Drama of BIrd Flight. New York: Doubleday and Company, Inc.

Tucker, V. A. (1966). Oxygen consumption of a flying bird. Science. 154, 150-151. 
(1968). Respiratory Exchange and Evaporative Water Loss in the Flying Budgerigar. J. of Exp. Biol. $48,67-87$.

- (1971). Flight energetics in birds. American 2001. $11,115-124$.

and G. E. Parrott. (1970). Aerodynamics of gliding flight in a falcon and other birds. J. of Exp. Biol. $52,345-367$. and Schmidt-Koenig. (1971). Flight speed of birds in relation to energetics and wind directions. Auk. $88,97-107$.

Van Wormer, J. (1968). The World of the Canada Goose. New York: J. B. Lippincott Company.

Werth, I. (1958). The problem of flocking in birds. Proc. XII. Intern. Ornithol. Congr. 12, 744-748.

Williams, T. C. and T. J. Klonowsk1. (1976). Angle of Canada Goose $V$ flight formations measured by radar. Auk. 93, 554-559. 


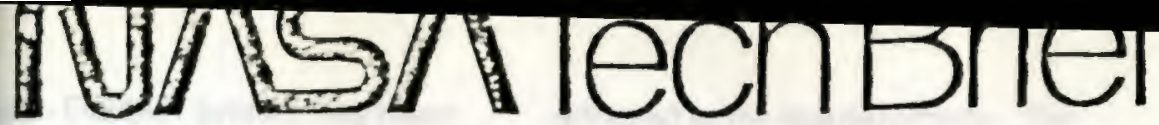

Nalional Aeronaulics and Space Admınısiration

\section{George C. Marshall Space Flight Center}

Alabama

\section{Laser-Doppler Measurement of Air Turbulence}

$\mathrm{A} \mathrm{CO}_{2}$ laser with a 10 -micron wavelength tracks

1-micron dust particles to measure air turbulence.

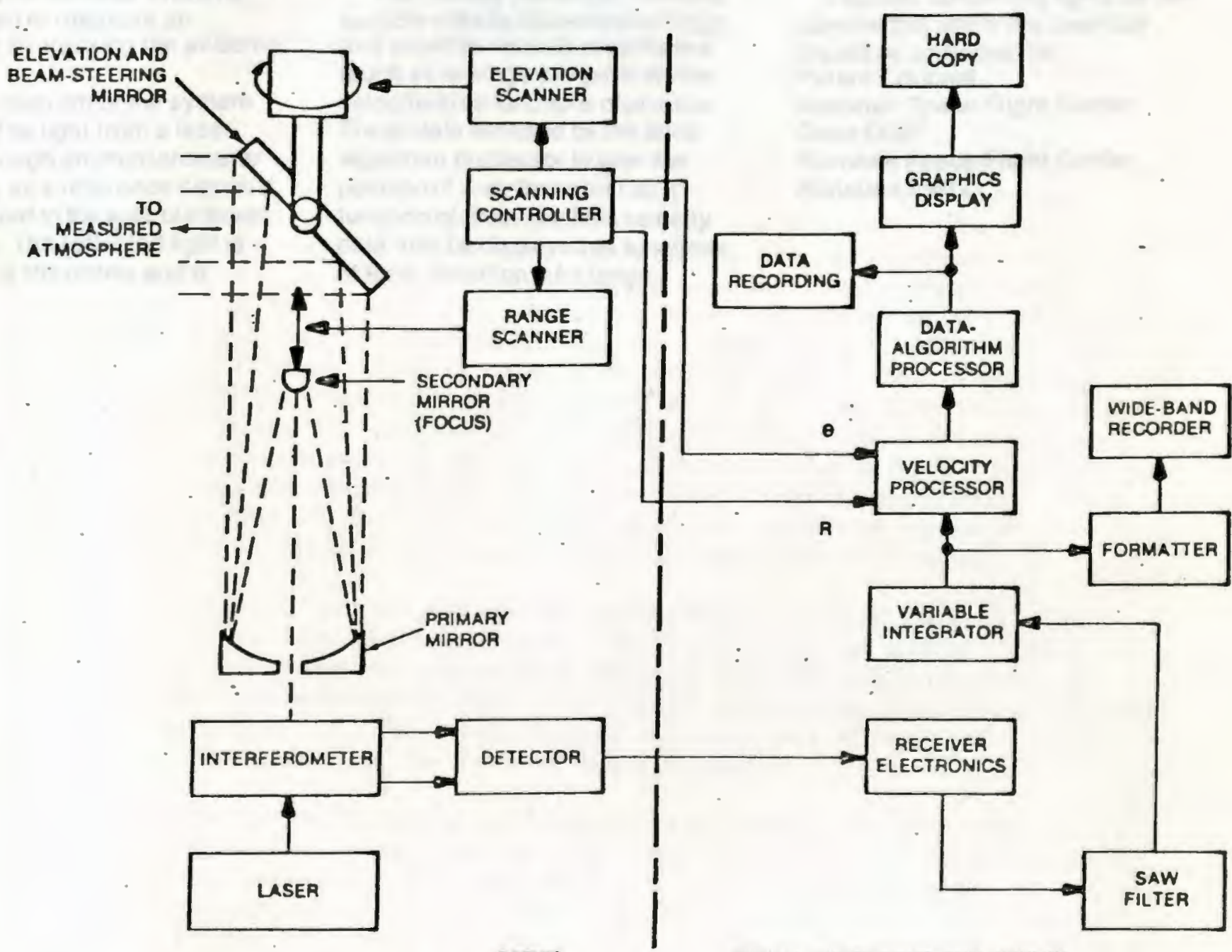

OPTICS

SIGNAL PROCESSING AND DISPLAY

The Laser-Doppler system shown is a one-dimensional system with provisions for scanning for range, along a vertical line, or on a single plane.

This is a reprint of an article from NASA Tech Brie/s, a quanerly publication distributed free to U.S. citizens to encourage commercial application of U.S. space technology. For information on publications and services avallable through the NASA Technology Uilization Program, write to the Director. Technology Utilization Office. P. O. Box 8756, BaltimorelWashington International Airpont, Maryland 21240. 
laser-Doppler system has been igned 10 delect air turbulence is intended for use at airports reasule and track aircraft trailing lexes. Laser-Doppler syslems ction similarly to radar. but cause of their much shorter velenglh. Ihey can detect very il particles such as atmospheric Since there is always dust in almosphere. Ihese syslems be used lo measure air vement by iracking the airborne licles.

Ablock diagram of the system hown. The light from a laser sses through an interferometer serves as a reference signal; it hen steered to the area of interest a mirror. The reflecled light is ked up by the mirror and is relurned to the inlerferometer. The oulput of the delector is a herio dyned signal which is rouled io the signal-processing electronics where it is filtered and integrated.

The remainder of the electronics processes the signal for display and controls the laser scan. The scanning controller coordinates the range tocus and the beam-steering mirror.

The velocity processor contains particle-velocity discrimination logic and provides velocity paramelers (such as average and peak vortex velocities) as functions of posilion. These dala are used by the datal algorithm processor to give the position of a vorlex center as a function of time. The final velocity dala may be displayed as funclions of lime, elevation, and range.
This work was done by Roberl $M$ Hufiaker of Marshall Space Flight Center. For further information. write:

Technology Utilization Officer Marshall Space Flight Center Code AT01

Marshall Space Flight Center. Alabama 35812

Reference: MFS-23155

Inquiries concerning rights for the commercial use of this invention should be addiessed to:

Patent Counsel

Marshall Space Flight Center Code $\mathrm{CCO} 1$

Marshall Space Flight Center, Alabama 35812 
The Marshall Space. Flight Center has developed Laser Doppler Systems for the measurement of atmospheric winds and turbulence. These systems have been proven as accurate remote wind veloclty sensors. Because of interest in the systems by the Federal Aviation Administration for use as an alrcraft trailing vortex detection and measuring system, an interagency agreement was slgned between NASA and the FAA to modify and Improve the exlsting Laser Doppler Systems. The systems are in use at the John F. Rennedy International Airport New York (KIA), to track the vortices generated by aircraft in the approach corridor lane of runway 31 R (Pig. 1).

The basic laser Doppler System consists of a very stable single frequency $\mathrm{CO}_{2}$ laser, a Mach-Zehnder interferometer, transmit-receive optics, infrared detector, a versatile range-angle scanner, velocityfrequency analyzer, data-algorithm processor, and display. The laser beam is directed optically and focused at the point of Interest in the atmosphere. The aerosol particles, always present in the atmosphere, scater some of the transmitted radiation in all directions, and since the particles move with the atmosphere, the frequency of the scattered light is doppler shifted from the frequency of the directed beam. Recelving optics collect the back scattered radiation and directs it onto an infrared detector where it is mixed with a small portion of the original beam. The total radiation seen by the detector fluctuates at a beat frequency which is a measure of the wind velocity at the point of interest. The Laser Doppler System measures the wind velocity component which is in the direction of the sensor line-of-sight (along the laser beam).

The principle is the same as in conventional doppler radars. The primary difference is the wavelength. The wavelength of conventional radars is of the order of centimeters whereas the $\mathrm{CO}_{2}$ laser wavelength is 10 microns. " Conventional radar can detect scattering from large objects (tens of centimeters). The Laser Doppler System sees objects of $1 \mathrm{micr}$ on in size corresponding to the dust in the atmosphere.

The airport configuration of this system consists of two scanning laser doppler system units, scanning in range and elevation perpendicular to the landing corridor. The two units are located approximately 800 feet apart and approximately 400 feet from the centerline of the landing corridor. At the JFK International Airport, they are positioned near the middle marker, 2500 feet from the end of the runway.

A vertical plane across the approach corridor is scanned in order to determine the tracks of the aircraft vortices. These detected vortices are monitored and displayed as they move across the scan plane. The tangential velocity profile of the vortex is also measured and recorded for later data evaluation. 